\title{
PROTECCIÓN DE LOS MENORES NO ACOMPAÑADOS (MENAS) EN EL DERECHO INTERNACIONAL; ESPECIAL ATENCIÓN A LA SITUACIÓN DE LOS NIÑOS SIRIOS*
}

\author{
PROTECTION OF UNACCOMPANIED MINORS IN INTERNATIONAL LAW; \\ REMARKS ABOUT THE SYRIAN CHILDREN
}

\author{
HANI Al RACHED**
}

Resumen: La guerra en Siria iniciada en 2011 ha provocado una serie de conflictos y disturbios en la zona del Oriente Medio. Entre sus consecuencias más graves se sitúa el desplazamiento forzado de millones de integrantes de la población siria, cruzando las fronteras regionales e internacionales en busca de un lugar más seguro. Entre los refugiados sirios se encuentran miles de menores desprotegidos y sin compañía de su familia. El presente trabajo trata de estudiar las medidas de protección de los menores no acompañados en virtud del Derecho Internacional, prestando especial atención a la situación de los menores refugiados sirios.

Palabras clave: Derecho Internacional, menores no acompañados, refugiados, medidas de protección.

Abstract: Since the war in Syria started in 2011 it has caused a series of conflicts and disturbances in the Middle East. Among its most serious consequences one may find is the forced displacement of millions of the Syrian population crossing regional and international borders searching for a safer place. There are thousands of undefended and unaccompanied minors among this population. This paper analyses the legal protection for these minors under International Law, paying special attention to the situation of Syrian refugee minors.

Keywords: International Law, unaccompanied minors, refugee, measures of protection.

SUMARIO: I. INTRODUCCIÓN; II. EL MENOR EN EL DERECHO INTERNACIONAL Y EL CONCEPTO DE MENORES EXTRANJEROS NO ACOMPAÑADOS; 1 . Concepto de la minoría de edad; 2 . El tratamiento de menor extranjero no acompañado; 3. Motivos de la inmigración de los menores extranjeros no acompañados; III. MEDIDAS DE PROTECCIÓN DE LOS MENORES NO ACOMPAÑADOS EN EL ÁMBITO JURÍDICO INTERNACIONAL; 1. La protección de los menores no acompañados en el Derecho español; 2. La protección de los menores no acompañados en el ámbito jurídico internacional; A. Convención sobre los Derechos del Niño de

* $\quad$ http://doi.org/10.15366/rjuam2019.39.001

Fecha de recepción: 18 de enero de 2019.

Fecha de aceptación: 11 de abril de 2019.

** Doctor en Derecho graduado por la Universidad de Zaragoza, especialista en Derecho Internacional y Derecho de Familia, correo de contacto: hanisiria@hotmail.com. 
20 de noviembre de 1989; B. Resolución del Consejo de 26 de junio de 1997 relativa a los menores no acompañados nacionales de países terceros (97/C 221/03); C. Comunicación de la Comisión Europea al Parlamento y al Consejo de Europa; IV. SITUACIÓN ACTUAL DE LOS MENORES REFUGIADOS SIRIOS: UNA GENERACIÓN PERDIDA; 1. Los niños sirios constituyen la parte más afectada por la guerra siria; 2. Medidas de protección en caso de los menores refugiados sirios; A. El asilo; B. La reagrupación familiar; C. Integración de los menores sirios en familias que pertenecen a su origen cultural; D. La protección de los menores no acompañados mediante la institución de la Kafala; E. El retorno de los menores sirios no acompañados a su país; F. Firmar un acuerdo con el gobierno sirio; V. COMPETENCIA JUDICIAL INTERNACIONAL Y LEY APLICABLE EN MATERIA DE PROTECCIÓN DE LOS MENORES REFUGIADOS Y DESPLAZADOS; 1. Competencia judicial internacional en materia de protección de los menores refugiados y desplazados; 2 . La ley aplicable en materia de protección de los menores refugiados y desplazados; VI. CONCLUSIONES; VII. BIBLIOGRAFÍA.

\section{INTRODUCCIÓN}

El presente trabajo trata de estudiar la responsabilidad de la protección de los menores extranjeros no acompañados y las medidas empleadas en el marco del Derecho Internacional, prestando especial atención a los niños refugiados sirios. Asimismo, entre las materias abordadas en el trabajo, están la competencia judicial internacional y ley aplicable a las medidas de protección en caso de los niños refugiados y desplazados.

No cabe duda de que los menores extranjeros no acompañados constituyen el conjunto más necesitado dentro del sistema de protección de menores. La ausencia de una persona adulta responsable de ellos, junto con su condición como menores de edad, exige tomar medidas legales convenientes en el marco de los convenios internacionales y el Derecho internacional. Los menores extranjeros no acompañados, refugiados y desplazados, (en lo sucesivo MENAS ${ }^{1}$ ), se encuentran en situación de desamparo y están expuestos a todo tipo de violaciones, la trata o el tráfico de menores, trabajo forzoso y negación de educación y atención sanitaria ${ }^{2}$. Desde el año 2015, miles de menores refugiados desaparecieron en diversas partes del continente europeo. El último dato ha sido de la Oficina de Investigación Criminal Germana (en adelante, BKA) en el 24 de diciembre de $2018^{3}$. Según la BKA hay más de 7.000 menores de edad desaparecidos llegados a Alemania, de los cuales unos 3.500

\footnotetext{
1 A lo largo de este estudio se deberá usar el término «MENAS» para referirse al grupo de Menores Extranjeros no Acompañados. En España, el término MENAS apareció a mediados de la década de los años 90, BRAVO RODRÍGUEZ, Ma ${ }^{\mathrm{a}}$, La situación de menores no acompañados en España, Conferencia regional sobre «las Migraciones de los menores no acompañados; actuar de acuerdo con el interés superior del menor», celebrada en el Marco del Consejo de Europa, Torremolinos, Málaga, 2005, p. 2.

2 ARCE FERNÁNDEZ, I., Cuaderno Recopilatorio de Legislación Relativa a Menores de Edad, Oviedo (Consejería de Servicios y Derechos Sociales del Principado de Asturias), 2017, p. 344.

3 En Alemania hay más de 11.000 personas desaparecidas, artículo publicado en Dw. Disponible en: <https://www.dw.com/es/en-alemania-hay-m\%C3\%A1s-de-11000-personas-desaparecidas/a-46852979>. [Consultado el 28/12/2018].
} 
menores refugiados ${ }^{4}$. La agencia policial europea recela de que los menores podrían estar esclavizados por mafias de explotación sexual ${ }^{5}$. Según los datos ofrecidos por EUROSTAT y FRONTEX «la llegada de menores migrantes no acompañados no es un fenómeno circunstancial o temporal, sino una característica en realidad preocupante de la inmigración hacia el territorio de la Unión Europea» ${ }^{6}$.

La inmigración de menores extranjeros sin estar acompañados por adultos responsables de su cuidado a un país en el que no obtienen la residencia legal provoca diversos problemas de tipo jurídico, en cuanto a las medidas de protección que se deben tomar. Por otro lado, se plantean también interrogantes en el marco del Derecho internacional privado en el ámbito de la Competencia judicial internacional y, de forma posterior, de la Ley aplicable a las medidas de protección en caso de los niños refugiados y desplazados no acompañados.

\section{EL MENOR EN EL DERECHO INTERNACIONAL Y EL CONCEPTO DE MENORES EXTRANJEROS NO ACOMPAÑADOS}

En el panorama europeo el fenómeno migratorio de los menores extranjeros no acompañados o «MENAS» apareció entre los años 1980 y 19907, con excepción de Alemania que lleva recibiendo a jóvenes solicitantes de asilo desde los finales del año $1970^{8}$. El fenómeno ha vuelto a ponerse de manifiesto en el año 2014 en los países de la Unión Europea con la presencia de numerosos menores sirios huidos de la guerra en Siria ${ }^{9}$. Actualmente, no se pueden dar datos precisos del número de MENAS que se encuentran en cada Estado miembro. En la mayoría de los casos las cifras se refieren al número de los menores entregados en los centros del sistema de protección durante un periodo de tiempo determinado ${ }^{10}$.

En algunos Estados europeos, como Reino Unido, Alemania y Bélgica, ofrecen datos solo de las solicitudes de asilo presentadas por los menores extranjeros no acompañados.

4 De nuevo, en Alemania hay más de 11.000 personas desaparecidas, artículo publicado en Dw. Disponible en: $<$ https://www.dw.com/es/en-alemania-hay-m\%C3\%A1s-de-11000-personas-desaparecidas/a-46852979>. [Consultado el 28/12/2018].

5 Desaparecen diez mil niños refugiados y Europa los ignora, artículo publicado en telesurtv.net. Disponible en: <https://www.telesurtv.net/news/Desaparecieron-10-mil-ninos-refugiados-y-Europa-losignora-20161029-0030.html $>$. [Consultado el 03/10/2018].

6 Menores migrantes no acompañados en la Unión Europa, artículo publicado en Foreign Affairs. Disponible en: $<$ http://revistafal.com/menores-migrantes-no-acompanados-en-la-union-europea/ $>$. [Consultado el 04/10/2018].

7 QUIROGA, V., ALFONSO, A. Y SORIA, M., «Menores migrantes no acompañados en España, Sueños del Bolsillo», en Informe elaborado por la Grupo de Investigación IFAM, Madrid, 2010, p. 20.

8 SENOVILLA HERNÁNDEZ, D., «Situación y tratamiento de los menores extranjeros no acompañados en Europa, Un Estudio comparado de 6 países: Alemania, Bélgica, España, Francia, Italia, y Reino Unido», Observatorio internacional de Justicia Juvenil, Bélgica, 2007, pp. 21-23.

9 AMAIA BRAVO, Ma; SANTOS-GONZÁLES, I., «Menores extranjeros no acompañados en España: necesidades y modelos de intervención», Psychosocial Intervention, vol. 26, 2017, pp. 55-62.

10 SENOVILLA HERNÁNDEZ, D., «Situación y tratamiento de los menores extranjeros», ob. cit., p. 25. 
Sin embargo, algunos estudios señalan que la inmigración de los menores no acompañados está en un aumento progresivo. Según los datos ofrecidos por Eurostat, «entre los años 2013 y 2014 la cifra se duplicó de 12.730 a 23.150. En 2015 alcanzó un total de 106.000» ${ }^{11}$.

En conclusión, las cifras proporcionadas por diferentes países de los menores no acompañados no reflejan el número total sino que se refieren a los menores entregados en los centros del sistema de protección durante un periodo de tiempo determinado.

No obstante, cabe distinguir, de forma necesaria, entre dos concepciones distintas:

1. El menor de edad «en general»

2. El menor extranjero «no acompañado»

\section{Concepto de la minoría de edad}

Existen diversas definiciones que determinan el concepto del menor de edad, si bien, la mayoría concuerdan con que los menores son aquellos individuos menores de dieciocho años. En este estudio hemos seleccionado dos concepciones mencionadas en los tratados internacionales más importantes. El art. 1 de la Convención sobre los Derechos del Niño, define el menor como «todo ser humano menor de dieciocho años de edad, salvo que, en virtud de la ley que le sea aplicable haya alcanzado antes la mayoría de edad». Por su parte, el art. 2 del Convenio de La Haya de 19 de octubre de 1996, relativo a la Competencia, la Ley aplicable, el Reconocimiento, la Ejecución y la Cooperación en materia de la Responsabilidad Parental y de Medidas de Protección de los Niños, dispone que «el Convenio se aplica a los niños a partir de su nacimiento y hasta que alcancen la edad de 18 años». Es por ello que se puede deducir de los textos citados que el menor es un individuo que aún no ha alcanzado la mayoría de edad antes de los 18 años y como tal debe ser protegido.

En el ámbito del Derecho internacional encontramos otro grupo de menores que necesitan el cuidado y la protección, esto es, los menores extranjeros no acompañados.

\section{EI tratamiento de menor extranjero no acompañado (MENA)}

El concepto de menores extranjeros no acompañados o «MENA» es conocido en todas las partes de la Unión Europea. En Alemania se conocen por (unaccompanied asylum seeking minors), es decir, menores no acompañados solicitantes de asilo. En el Reino Unido se les dan un nombre parecido, se denominan por (unaccompanied refugee minors) «menores no acompañados refugiados». En cambio, en Francia se utilizan el término «mineurs étrangers

\footnotetext{
11 Menores migrantes no acompañados en la Unión Europa, artículo publicado en Foreign Affairs. Disponible en: $<$ http://revistafal.com/menores-migrantes-no-acompanados-en-la-union-europea/>. [Consultado el 04/10/2018].
} 
isolés» o menores extranjeros aislados ${ }^{12}$. Los autores y juristas franceses utilizan este término, es decir «aislados» y no refugiados, dado que este colectivo expresa en la mayoría de los casos de los menores extranjeros que no tienen un representante legal en el territorio francés ${ }^{13}$.

De hecho, el concepto de MENAS no siempre se expresa el mismo sentido. En los textos de las Naciones Unidas la concepción tiene un carácter general, esto es, no incluye la condición de ser extranjero o inmigrante sino que abarca a todos los menores no acompañados. Mientras que, en las resoluciones declaradas por las instituciones de la Unión Europea el concepto es más limitado, se refiere los menores nacionales de países terceros que lleguen al territorio de los Estados europeos.

La Observación General número 6, elaborada por el Comité de los Derechos del niño de las Naciones Unidas en el año 2015, define los menores no acompañados como «los menores que están separados de ambos padres y otros parientes y no están al cuidado de un adulto al que, por ley o costumbre, incumbe esa responsabilidad». El Alto Comisionado de las Naciones Unidas para los Refugiados (ACNUR) comparte el mismo concepto. Según la fundación ACNUR los menores no acompañados son «los niños y adolescentes menores de 18 años que se encuentran fuera del país de origen y están separados de ambos padres o de la persona que por ley o costumbre les tuviera a su cargo. Algunos de estos menores están totalmente solos, mientras que otros conviven con otros familiares» ${ }^{14}$.

Por su parte, el artículo 1 de la Resolución del Consejo Europeo de 26 de junio de $1997^{15}$, especifica que son «los menores de 18 años nacionales de países terceros que lleguen al territorio de los Estados miembros sin ir acompañados de un adulto responsable de los mismos, ya sea legalmente o con arreglo a los usos y costumbres, en tanto en cuanto no estén efectivamente bajo el cuidado de un adulto responsable de ellos». La misma Resolución añade que el ámbito de aplicación del art. 1 abarca a los menores nacionales de países terceros que, «después de haber entrado en el territorio de los Estados miembros, sean dejados solos». Mientras que, la Directiva 2011/95/UE del Parlamento Europeo y del Consejo de 13 de diciembre de 2011 ${ }^{16}$, define los menores no acompañados como «el menor de 18 años no nacional de la Unión Europea o apátrida que llegue al territorio de los Estados miembros sin ir acompañado de un

12 SENOVILLA HERNÁNDEZ, D., «Situación y tratamiento de los menores extranjeros no acompañados en Europa», ob.cit., p. 5.

13 BÉNÉDICTE MASSON., " "Mineurs isolés étrangers": le sens d'une appellation», Migrations Société, 2010/3-4, (N 129-130), pp. 115-128. Disponible en: <https://www.cairn.info/revue-migrations-societe2010-3-page-115.htm\#>. [Consultado el 18/03/2019].

14 Alto Comisionado de las Naciones Unidas para los Refugiados (ACNUR): Guía y procesos en la atención a niños sin acompañantes solicitantes de asilo, 1997, disponible en: $<$ https://www.unicef.es/sites/unicef.es/files/ Suenos_de_bolsillo.pdf $>$.

15 Resolución del Consejo de 26 de junio de 1997 relativa a los menores no acompañados nacionales de países terceros (97/C 221/03). Disponible en: <https://eur-lex.europa.eu/legal-content/ES/ ALL/?uri=CELEX:31997Y0719(02)>.

16 Directiva del Parlamento Europeo y del Consejo de 13 de diciembre de 2011 (2011/95/UE). Disponible en:<https://web.icam.es/bucket/DIRECTIVA\%2095\%202011\%20CALIFICACION\%20L00009-00026.pdf>. 
adulto responsable de él, ya sea legalmente o con arreglo a la práctica, mientras tal adulto no se haga efectivamente cargo de él; incluyendo al menor que deje de estar acompañado después de haber entrado en el territorio de los Estados miembros» ${ }^{17}$.

A la luz de las definiciones ofrecidas se puede deducir que las características que definen este grupo son los siguientes: 1. la minoría de edad; 2 . la ausencia de una persona adulta responsable; y 3 . ser extranjero o no nacional. De este modo, el concepto de MENAS se refiere a todo menor de dieciocho años de edad separado de su familia totalmente, o bien, sin la compañía de personas responsables de su cuidado según lo que establece la ley o la costumbre; y que se encuentra en el territorio de un Estado que no es el de su nacionalidad o su residencia habitual.

Para resolver el problema de la inmigración de los menores extranjeros no acompañados es necesario conocer los motivos que empujan a estos menores a abandonar su país de origen e inmigrar a otro Estado distinto.

\section{Motivos de la inmigración de los menores extranjeros no acompañados}

«La protección de los menores migrantes empieza por abordar las causas profundas que conducen a tantos de ellos a embarcarse en viajes peligrosos hacia Europa ${ }^{18}$. Los motivos que empujan a los menores no acompañados a desplazarse a otros países son diversos, si bien, algunos investigadores determinan dos factores principales: económicos y políticos ${ }^{19}$. Bravo Rodríguez afirma que «los principales motivos vienen dados por razones económicos y políticos $\rangle^{20}$. El menor que llega a España, como señala Bravo Rodríguez, tiene un proyecto claro: conseguir la documentación y trabajar, mejorar su situación personal y familiar ${ }^{21}$. La mayoría de los menores vienen a Europa sin formación educativa o profesional con lo que necesitan un cierto tiempo para conseguir esa formación profesional para trabajar y ganar dinero para ayudar a sus familias. En cuanto a las razones políticas, Senovilla Hernández señala que «los menores no acompañados pueden buscar la protección del asilo a causa de sufrir un miedo a ser perseguidos o por encontrarse sin protección a causa de violaciones

17 Directiva 2011/95/UE del Parlamento Europeo y del Consejo de 13 de diciembre de 2011, Art. 2, (párr. K y L).

18 Comunicación de la Comisión al Parlamento Europeo y al Consejo, Protección de los menores migrantes, Bruselas, 2017, p. 4.

19 SENOVILLA HERNÁNDEZ, D., «Situación y tratamiento de los menores extranjeros no acompañados en Europa», ob. cit., p. 29; ETIEMBLE, A., Les mineurs isolés étrangers en France, Evaluation quantitative de la population accueillie á lAide Sociale á lEnfance - Les termes de l'accueil et la prise en charge, Rennes (Quest'us), 2002, y BLOCQUAUX, J., BUSTIN, A., \& GIORGI, D., «Mission d'analyse et de proposition sur les conditions, d'accueil des mineurs étrangers isolés en France», Paris (Inspection Générale des Affaires Sociales, IGAS), 2005.

20 BRAVO RODRÍGUEZ, Ma., La situación de menores no acompañados en España, ob. cit., pp. 7-8.

21 BRAVO RODRÍGUEZ, Ma ., La situación de menores no acompañados en España, ob. cit., p. 8. 
de derechos humanos, conflictos bélicos o disturbios en su propio país $\rangle^{22}$. Según un estudio realizado por Senovilla Hernández, en Alemania y Reino Unido, los motivos son políticos, en general los menores solicitan el asilo; mientras que en España e Italia, son económicos ${ }^{23}$.

En caso de los menores sirios el motivo principal que impulsó a las familias sirias y/o sus hijos a abandonar su país es el conflicto armado y las situaciones catastróficas que viven la población siria, es decir, no cuentan con los mínimos recursos básicos de la vida, sin agua, luz y alimentación. La situación de los niños sirios no se puede comparar con otros grupos de menores inmigrantes que acceden a los países europeos, como por ejemplo, los menores marroquíes que en la mayoría de los casos inmigran por causas económicas ${ }^{24}$. Mientras que, el refugio de los menores sirios en los Estados europeos no suele tener bases económicas. Esto es, la inmigración de los menores sirios no responde a una decisión planificada, tal como ocurre con los menores marroquíes que inmigran a Europa. El desplazamiento de MENAS de nacionalidad siria se ha generado de forma forzosa debido a la guerra de su país; y de forma indirecta, por motivo del cierre de las fronteras por parte de los países europeos del Este y los Balcanes. Este último motivo es el que obligó a los niños sirios a separarse de sus familias y cruzar las fronteras solos. Sea cual sea el motivo, las condiciones en las se encuentran estos niños, es decir, menores de edad, fuera del país de su origen y no acompañados por otros adultos responsables de los mismos, les convierte en un grupo vulnerable que debe ser objeto de protección por las instituciones internacionales.

La Unión Europea para hacer frente al fenómeno migratorio de los menores extranjeros no acompañados ha elaborado diversos planes estratégicos dirigidos hacia la protección efectiva de los menores. Entre los programas promovidos, se encuentra el Plan de Acción sobre Menores no Acompañados (2010-2014) ${ }^{25}$. El objetivo del Plan era la prevención de la migración insegura y la cooperación con los países de origen y tránsito, mediante la organización de programas que protegen a los menores en sus países. Entre los ámbitos que abarca el programa, hay que citar la reducción de la pobreza y mejorar el sistema de la educación, la salud y la política laboral. Según la Comunicación de la Comisión al Parlamento Europeo y al Consejo sobre el Plan (2010-2014), estos programas podrían tratar las causas profundas de la migración de los menores inmigrantes ${ }^{26}$, y por tanto les permitiría crecer en sus países de origen con buenas perspectivas de desarrollo personal y un nivel digno de vida.

Después de aclarar el concepto del menor no acompañado y los motivos que empujan a los MENAS a abandonar su país de origen e inmigrar a otro Estado distinto, en la segunda

22 SENOVILLA HERNÁNDEZ, D., «Situación y tratamiento de los menores extranjeros no acompañados en Europa», ob. cit., p. 6.

23 SENOVILLA HERNÁNDEZ, D., «Situación y tratamiento de los menores extranjeros no acompañados en Europa», ob.cit. p. 30.

24 SENOVILLA HERNÁNDEZ, D., «Situación y tratamiento de los menores extranjeros no acompañados en Europa», ob. cit., p. 29.

25 Plan de Acción sobre Menores no Acompañados (2010-2014). Disponible en: <https://eur-lex.europa. eu/LexUriServ/LexUriServ.do?uri=COM:2010:0213:FIN:es:PDF>.

26 Plan de Acción sobre Menores no Acompañados (2010-2014). 
parte de este trabajo tratamos de estudiar las medidas de protección de los menores en el ámbito jurídico internacional.

No cabe duda de que la llegada de menores no acompañados a un país que no sea el de su origen plantea muchos problemas de tipo jurídico, en cuanto a las medidas que se deben tomar, o bien cómo se debe prestar la asistencia necesaria a este grupo. A continuación, abordamos los principios y las medidas que forman el marco del sistema de la protección de los menores extranjeros no acompañados, tal como están regulados en los Convenios internacionales y el Derecho internacional.

\section{MEDIDAS DE PROTECCIÓN DE LOS MENORES NO ACOMPAÑADOS EN EL ÁMBITO JURÍDICO INTERNACIONAL}

Antes de comenzar con las normas y medidas que establecen el sistema de la protección del menor no acompañado es conveniente aclarar la naturaleza de las medidas de protección del menor y su alcance institucional.

A la vista de la Ley Orgánica 1/1996 de 15 de enero, modificada por la Ley Orgánica 8/2015 de 22 de julio de modificación del sistema de protección a la Infancia y a la Adolescencia $^{27}$, las medidas de protección de los menores representan una serie de instrumentos legales dirigidos a proteger a los niños y menores en diferentes circunstancias, esto es, en situación de desamparo o riesgo. Como regla general, los padres o los progenitores son los responsables legalmente del menor, de modo que cubren todas sus necesidades básicas. En ausencia de los padres u otras personas del círculo familiar, la responsabilidad de los menores se traslada a las organizaciones nacionales e internacionales donde se encuentran los menores. Los expertos del Derecho internacional privado concuerdan con esta idea. De acuerdo con Calvo Caravaca y Carrascosa González, en cuanto a las medidas de protección del menor, puede decirse que «se trata de medidas que deben ser adoptadas necesariamente por autoridades públicas de un Estado contratante. Tales medidas deben ir dirigidas a la protección de la persona o bienes del niño y pueden incluir medidas de atribución, ejercicio y privación total o parcial y delegación de la responsabilidad parental» ${ }^{28}$.

Para comprender el marco jurídico que regula la protección de los MENAS se realizará una referencia breve al sistema de la protección de los menores extranjeros no acompañados en el Derecho español. Luego, en el siguiente apartado estudiamos los derechos de los menores y las medidas que les protegen en el ámbito de las convenciones internaciones y también las cuales establecidas a nivel de la Unión Europea.

27 BOE núm. 175, de 23 de julio de 2015, páginas 61871 a 61889, Ley Orgánica 1/1996, de 15 de enero, modificado por la Ley Orgánica 8/2015, de 22 de julio, de modificación del sistema de protección a la Infancia y a la Adolescencia.

28 CALVO CARAVACA, A. Y CARRASCOSA GONZÁLEZ, J., Derecho Internacional Privado, vol. II, ed.18 , Granada, (Comares) 2018, p. 451. 


\section{La protección de los menores no acompañados en el Derecho español}

No cabe duda de que la inmigración de los menores extranjeros no acompañados constituye una cuestión preocupante para el Estado español, no solo desde el punto de vista económico sino social y legal. España constituye uno de los preferentes distintos para los menores inmigrantes. La mayoría de los MENAS proceden de los países de África: Marruecos, Argelia y África Subsahariana y también de Pakistán ${ }^{29}$. «El sur del territorio peninsular como el archipiélago canario constituyen un punto de entrada principal de los flujos migratorios provenientes del continente africano ${ }^{30}$.

Según la fundación Save The Children, llegaron a España en el año 2014 unos 795 niños sirios solos o separados de sus progenitores, convirtiéndose en el segundo colectivo más representado, después los MENAS marroquíes, en los sistemas de protección de menores ${ }^{31}$. Sin embargo, esta cifra se ha reducido mucho en los últimos 3 años, en el 2017 había solo 49 menores acogidos ${ }^{32}$. El total de los niños sirios tutelados por la Administración Pública española, desde el año 2014 hasta 2018, alcanzó $1.069^{33}$.

El menor extranjero que se encuentra en España está protegido por las legislaciones nacionales y también las autonómicas, en particular, la Ley Orgánica 1/1996 de Protección Jurídica del Menor, modificado por la Ley Orgánica 8/2015 de 22 de Julio de modificación del sistema de protección a la Infancia y a la Adolescencia. Asimismo, la Ley Orgánica de 2/2009, de 11 de diciembre (reforma de la Ley 4/2000), sobre derechos y libertades de los extranjeros en España y su integración social se aplica a los menores extranjeros. Efectivamente, las leyes señaladas constituyen el marco jurídico general en materia de protección de los niños y los menores extranjeros no acompañados en España. En el ámbito autonómico se encuentran otras normativas que se aplican a los menores, así como la Ley 1/1995 del Principado de Asturias de 27 de enero de Protección del Menor, y también la Ley de 1/2006 de 28 de febrero de protección de menores de la Rioja, y por último la Ley de la Comunidad Autónoma de Cataluña de 14/2010 de 27 de mayo de los derechos y oportunidades en la infancia y la adolescencia ${ }^{34}$. Junto con las leyes nacionales y autonómicas «la protección del menor no acompañado en España está enmarcada por los instrumentos internacionales

29 CALVO CARAVACA, A. Y CARRASCOSA GONZÁLEZ, J., Derecho Internacional Privado, ob. cit., p. 428; BRAVO RODRÍGUEZ, Mª., La situación de menores no acompañados en España, ob. cit., p. 2.

30 SENOVILLA HERNÁNDEZ, D., «Situación y tratamiento de los menores extranjeros», ob. cit., p. 51.

31 Save The Children, «Los más solos: Los fallos en el sistema de acogida, protección e integración de los menores migrantes no acompañados que llegan a España», mayo 2018, p. 49.

32 Save The Children, «Los más solos: Los fallos en el sistema de acogida, protección e integración de los menores migrantes no acompañados que llegan a España», ob. cit., p. 48.

33 SENOVILLA HERNÁNDEZ, D., «Situación y tratamiento de los menores extranjeros», ob. cit., p. 48.

34 ALLUEVAAZNAR, L., «Situaciones de riesgo y desamparo en la protección de menores», Revista para el Análisis del Derecho Indret, 4/2011, p. 8. 
en que España es parte, en particular el Convenio sobre los Derechos del Niño de 20 de noviembre de $1989 »{ }^{35}$.

En el ámbito nacional, la Ley Orgánica 1/1996, modificada por la Ley Orgánica 8/2015, concede a los menores una serie de derechos. Según Bravo Rodríguez «los menores extranjeros no acompañados gozan de protección jurídica en España, así como de los derechos que reconoce la Convención Internacional de los Derechos del Niño ratificada por España, y de todos los derechos reconocidos por la normativa nacional en materia de protección de menores y extranjería y por la normativa autonómica» ${ }^{36}$. Entre los derechos reconocidos por la Ley Orgánica 1/1996, el derecho a la educación (art. 10.3), la asistencia sanitaria (art. 10.3), la libertad religiosa (art. 6) y la libertad de expresión (art. 8). El art. 10 en el párrafo 3 de la Ley Orgánica 1/1996 dispone que «los menores extranjeros que se encuentran en España tienen derecho a la educación, asistencia sanitaria y servicios y prestaciones sociales básicas, en las mismas condiciones que los menores españoles»».

España firmó desde el año 2005 convenios con tres países de donde más proceden los ME$\mathrm{NAS}^{37}:$ 1) con Rumanía el 15 de diciembre de 2005, en el ámbito de la protección de los menores de edad rumanos no acompañados en España, su repatriación y la lucha contra la explotación de los mismos ${ }^{38}$; 2) con la República de Senegal el 5 de diciembre de 2006 en el ámbito de la prevención de la emigración de menores de edad senegaleses no acompañados, su protección, repatriación y reinserción ${ }^{39}$; y 3) con Reino de Marruecos el 6 de marzo de 2007, en el ámbito de la prevención de la inmigración de menores no acompañados, su protección y su retorno ${ }^{40}$.

Por último, el Comité de Derechos del Niño de Naciones Unidas ha enviado en 22 de enero de 2018 un listado de observaciones al Gobierno español para modificar el Protocolo Marco de actuación con menores extranjeros no acompañados. Entre las directrices remitidas al Gobierno español es adoptar nuevas medidas para asegurar que los niños que llegan son identificados de forma correcta como tales en la frontera, mejorar su acceso al

35 REQUEJO ISIDRO, M., «La protección del menor no acompañados solicitante de Asilo: Entre Estado competente y Estado responsable», Cuadernos de Derecho Transnacional, vol. 9, n. . 2, 2007, p. 485.

36 BRAVO RODRÍGUEZ, Ma ., La situación de menores no acompañados en España, ob. cit., p. 11.

37 TRINIDAD NUÑEZ, P., «Los acuerdos celebrados por España en materia de menores extranjeros no acompañados en el contexto del marco jurídico de protección de los Menores extranjeros separados o no acompañados», en FRANCISCO ALDECOA, L.; JOAQUIM-J. FORNER D., (dirs.), La protección de los niños en el Derecho internacional y en las relaciones internacionales. Jornadas en conmemoración del 50 aniversario de la Declaración Universal de los Derechos del Niño y del 20 aniversario del Convenio de Nueva York sobre los Derechos del niño, Madrid (Marcial Pons), 2010, pp.267-271.

38 BOE núm. 195, de 16 de agosto de 2006.

39 BOE núm. 173, de 18 de Julio de 2008.

40 BOE núm. 70, de 22 de Marzo de 2013; TRINIDAD NUÑEZ, PILAR., «Los acuerdos celebrados por España en materia de menores extranjeros no acompañados en el contexto del marco jurídico de protección de los Menores extranjeros separados o no acompañados», ob. cit. 
procedimiento de asilo y garantizar condiciones adecuadas en los centros donde se les aloja, especialmente en Ceuta y Melilla ${ }^{41}$.

Después de conocer al sistema de la protección de los menores no acompañados en el Derecho español, en las próximas líneas tratamos de explicar los derechos y las medidas de protección de los MENAS previstos en los diferentes convenios y tratados internacionales, así como en las resoluciones ratificadas a nivel de la Unión Europea.

\section{La protección de los menores no acompañados en el ámbito jurídico internacional}

Respecto a las normas que establecen el sistema de la protección de los menores en el Derecho Internacional se extienden en diversos textos y convenciones internacionales. Algunos convenios tienen carácter general, como la Convención de Nueva York sobre los Derechos del Niño de $1989^{42}$. Mientras que, otros tratan temas específicos vinculados con la protección jurídica de los menores, así como el Convenio de La Haya de 1993, relativo a la Protección del Niño y a la Cooperación en Materia de Adopción Internacional ${ }^{43}$, y el Convenio de La Haya sobre Protección del Niño de 1996, relativo a la Competencia, la Ley aplicable y Medidas de Protección de los Niños ${ }^{44}$.

En la normativa de la Unión Europea, también hay distinguir entre normativa general y específica. Las organizaciones europeas oficiales, como el Consejo de Europa y el Parlamento Europeo, han establecidos diversos convenios, resoluciones y directrices en materia de la protección jurídica de los menores extranjeros no acompañados. Algunos Convenios afectan a los MENAS de forma indirecta, así como el Convenio Europeo de Derechos Humanos y el Convenio Europeo sobre Ejercicio de los Derecho de los niños ${ }^{45}$. Mientras que otros regulan la protección de los menores extranjeros no acompañados de forma específica y directa, como por ejemplo, las resoluciones del Consejo de Europa y del Parlamento Europeo.

41 La ONU urge a España a reformar el protocolo para menores extranjeros solos y a garantizar su identificación en frontera, artículo publicado en la revista electrónica EuropaPress. Disponible en: <http:// www.europapress.es/epsocial/migracion/noticia-onu-urge-espana-reformar-protocolo-menores-extranjerossolos-garantizar-identificacion-frontera-20180208192236.html>. [Consultado el: 25/09/2018].

42 BOE núm. 313, de 31 de diciembre de 1990, páginas 38897 a 38904, Convención de Nueva York sobre los Derechos del Niño de 1989.

43 BOE núm. 182, de 1 de agosto de 1995, páginas 23447 a 23454, Convenio de La Haya de 1993 relativo a la Protección del Niño y a la Cooperación en Materia de Adopción Internacional.

44 Convenio de La Haya sobre Protección del niño de 1996, relativo a la Competencia, la Ley aplicable y Medidas de Protección de los Niños, BOE núm. 291, de 2 diciembre de 2010 Disponible en: <https://www. boe.es/boe/dias/2010/12/02/pdfs/BOE-A-2010-18510.pdf >.

45 BOE núm. 45, de 21 de febrero de 2015, páginas 14174 a 14189, Instrumento de Ratificación del Convenio Europeo sobre Ejercicio de los Derecho de los niños, hecho Estrasburgo en el 25 de enero de 1996. 
Debido a la extensión del tema y su complejidad, la segunda parte del estudio se centrará solo en las disposiciones y las medidas de protección más destacadas en las convenciones internacionales y las resoluciones ratificadas a nivel de la Unión Europea. En primer lugar, explicamos los derechos y las medidas de protección a los menores en la Convención sobre los Derechos del niño de 20 de noviembre de 1989. En segundo lugar, aclaramos los mecanismos de protección a los menores establecidos en la Resolución del Consejo de 26 de junio de 1997, relativa a los menores no acompañados nacionales de países terceros. Por último, explicamos las últimas medidas de protección tomadas por la Comisión Europea en el 2017, especialmente en caso de los menores desaparecidos en el territorio de la Unión Europea.

\section{A. Convención sobre los Derechos del Niño de 20 de noviembre de 1989}

No cabe duda de que la Convención de Nueva York de 1989 sobre los Derechos del Niño de las Naciones Unidas ${ }^{46}$ es considerada como el principal texto internacional que afirma los derechos de los niños. La Convención de Nueva York determina una serie de derechos del niño: el principio de no discriminación, el interés superior del niño, derecho a la unidad familiar, derecho a expresar libremente su propia opinión, derecho a la protección de los niños privados de su medio familiar, derecho a la asistencia humanitaria y protección de los menores solicitantes de asilo. Junto a los derechos citados, el artículo 7 del Convenio declara que el niño después de su nacimiento tiene tres derechos fundamentales: un nombre, nacionalidad y conocer a sus padres y ser cuidado por ellos.

Los principios y derechos mencionados en el Convenio se deben aplicar a todos los niños, entre ellos los menores extranjeros no acompañados, tal como se establecen los artículos 1 y 2 de la Convención. El artículo 1 dispone que «se entiende por niño todo ser humano menor de dieciocho años de edad, salvo que, en virtud de la ley que le sea aplicable, haya alcanzado antes la mayoría de edad». Por su parte, el artículo 2 establece que los Estados Partes deben respetar los derechos enunciados en el Convenio y «asegurarán su aplicación a cada niño sujeto a su jurisdicción, sin distinción alguna, independientemente de la raza, el color, el sexo, el idioma, la religión, la opinión política o de otra índole, el origen nacional, étnico o social, la posición económica, los impedimentos físicos, el nacimiento o cualquier otra condición del niño, de sus padres o de sus representantes legales».

A la luz de los textos citados, los MENAS que se encuentran en un Estado Parte de la convención disfrutarán de todos los derechos enunciados en este convenio. Por un lado, los MENAS entran en el concepto a que se refiere el artículo 1 del Convenio de 1989, esto es, «menores de dieciocho años de edad». Por otro lado, el artículo 2 aclara que los Estados Partes deben aplicar las normas de la convención a todos los niños sujetos a su jurisdicción,

\footnotetext{
46 Convención de Nueva York de 1989 sobre los Derechos del Niño. Disponible en: < https://www.unicef. es/causas/derechos-ninos/convencion-derechos-ninos $>$.
} 
sea cual sea su origen nacional, étnico o social. En otras palabras, el Convenio excluye a todos los factores que podrían afectar a la aplicación del Convenio a los menores extranjeros no acompañados, así como la raza, el color, el sexo, el idioma, la religión, la opinión política y el origen nacional, étnico o social.

Los derechos declarados por la organización de las Naciones Unidades en el Convenio de 1989 han sido reforzados por medidas legislativas y administrativas. De acuerdo con el artículo 3 de la Convención, los Estados Partes se comprometen a asegurar al niño la protección y el cuidado que sean necesarios, y «tomarán todas las medidas legislativas y administrativas adecuadas». Asimismo, el Convenio de 1989 prevé en su artículo 39 que «los Estados Partes adoptarán todas las medidas apropiadas para promover la recuperación física y psicológica y la reintegración social de todo niño víctima de: cualquier forma de abandono, explotación o abuso; tortura [...] o conflictos armados».

Conforme al art. 39 los Estados Partes deben aportar a todo niño víctima de conflictos armados, como en el caso de los niños sirios, todas las medidas en cuanto a la recuperación física y psicológica y la reintegración social. La recuperación y reintegración, según el mismo artículo, «se llevarán a cabo en un ambiente que fomente la salud, el respeto de sí mismo y la dignidad del niño». Otra de las medidas de protección de los menores consiste en solicitar el estatuto de refugiado o el asilo. Los menores no acompañados cuando inmigran a otro Estado siempre se encuentran en una situación irregular, por eso, en su mayor parte solicitan el asilo como forma de protección. En virtud del apartado 1. ${ }^{\circ}$ del artículo 22: «los Estados Partes adoptarán medidas adecuadas para lograr que el niño que trate de obtener el estatuto de refugiado o que sea considerado refugiado de conformidad con el derecho y los procedimientos internacionales o internos aplicables reciba, tanto si está solo como si está acompañado de sus padres o de cualquier otra persona, la protección y la asistencia humanitaria adecuadas para el disfrute de los derechos pertinentes enunciados en la presente Convención y en otros instrumentos internacionales de derechos humanos o de carácter humanitario en que dichos Estados sean partes». Según el apartado 1. ${ }^{\circ}$ del art. 22, los Estados Partes deben adoptar medidas apropiadas en caso de los menores que solicitan el estatuto de refugiado o el asilo. Los menores solicitantes del asilo, disfrutarán de la protección y la asistencia humanitaria adecuadas no solamente cuando se encuentran solos en el territorio de un Estado Parte, sino también si están acompañados de sus padres o de cualquier otra persona.

Por último, de entre las responsabilidades de los Estados respecto a la protección de los menores destaca la de localizar a la familia del niño refugiado. En virtud del apartado 2. ${ }^{\circ}$ del artículo 22: «los Estados Partes cooperarán, en la forma que estimen apropiada, en todos los esfuerzos de las Naciones Unidas y demás organizaciones intergubernamentales competentes u organizaciones no gubernamentales que cooperen con las Naciones Unidas por proteger y ayudar a todo niño refugiado y localizar a sus padres o a otros miembros de su familia, a fin de obtener la información necesaria para que se reúna con su familia». El mismo apartado prevé que en las situaciones en que no se pueda localizar a ninguno 
de los padres o miembros de la familia, el menor «tendrá derecho a la misma protección que cualquier otro niño privado permanente o temporalmente de su medio familiar, por cualquier motivo».

A continuación, abordamos las medidas de protección tomadas en dos textos importantes declarados a nivel de la Unión Europea: la Resolución del Consejo de 26 de junio de 1997 relativa a los menores no acompañados nacionales de países terceros, y también la Comunicación de la Comisión Europea dirigida al Parlamento Europeo y al Consejo en 12 de abril de 2017.

\section{B. Resolución del Consejo de 26 de junio de 1997 relativa a los menores no acompañados nacionales de países terceros (97/C 221/03)}

Las instituciones de la Unión Europea han ratificado diversas Convenciones en el ámbito de la protección de los menores. El primer texto legislativo adoptado por la UE y dedicado a los menores no acompañados es la Resolución del Consejo de 26 de junio de 1997 ${ }^{47}$. Las normas que contiene la Resolución están inspiradas de la Convención sobre los Derechos del niño de 1989. En cuanto al ámbito de aplicación, la Resolución determina que sus disposiciones se aplican a los menores de dieciocho años nacionales de países terceros que entran al territorio de los Estados miembros sin ir acompañados por un adulto responsable de los mismos, ya sea legalmente o con arreglo a los usos y costumbres (art. 1). El mismo artículo dispone que la presente Resolución podrá aplicarse a los menores nacionales de países terceros que, después de su entrada al territorio de los Estados miembros, sean dejados solos. Respecto al propósito de la Resolución, se refiere a las directrices para el trato de los menores no acompañados respecto de su acogida, su estancia y retorno, así como del trato en caso de los solicitantes de asilo.

En cuanto al acceso del territorio de los Estados miembros el apartado $1 .^{\circ}$ del art. 2 de la Resolución exige que los menores deban disponer los documentos y autorizaciones requeridas para ello, en caso contrario, las autoridades del Estado podrán denegar la entrada al menor, salvo si los menores solicitan el asilo, en cuyo caso «se aplicará la Resolución relativa a las garantías mínimas aplicables al procedimiento de asilo y, en particular, los principios establecidos en los puntos 23 a 25 de la misma». El apartado 3. ${ }^{\circ}$ del mismo artículo prevé que si las normas de un Estado miembro exigen que los menores deban permanecer en la frontera hasta que se dicte resolución sobre su admisión al territorio o sobre su retorno, en este caso las autoridades de ese Estado deberían disponer de todo el apoyo material y los cuidados necesarios para satisfacer las necesidades básicas de los menores, como, por ejemplo, alimentación, alojamiento adecuado y así los servicios sanitarios (art. 2.3).

\footnotetext{
47 Resolución del Consejo de 26 de junio de 1997 relativa a los menores no acompañados nacionales de países terceros. Disponible en: <https://eur-lex.europa.eu/legal-content/ES/ALL/?uri=CELEX\%3A3199 $7 \mathrm{Y} 0719 \% 2802 \% 29>$.
} 
En caso de los solicitantes de asilo la Resolución de 1997 dispone en su art. 4 que «todos los menores no acompañados deberían tener derecho a solicitar asilo» (art. 4.1). No obstante, la Resolución determina una serie de requisitos para poder solicitar el asilo, entre ellos, que el menor debe presentar un justificante de su edad. Si el menor no tuviera dicho justificante, en este caso los Estados miembros podrían comprobar su edad mediante una prueba médica realizada por personal médico cualificado (art. 4.3). En relación a la repatriación de los menores no acompañados a sus países de origen, la Resolución de 1997 establece en su art. 5 que se recurre a esta medida cuando se reúnen en el país de origen del menor o un país tercero, las condiciones apropiadas para su acogida y asistencia, teniendo en cuenta las necesidades especiales del menor, su edad y su nivel de autonomía. En virtud del apartado $1 .^{\circ}$ del artículo 5, «cuando un menor de edad no sea autorizado a prolongar su estancia en un Estado miembro, este solo podrá devolverlo al país de origen o un país tercero dispuesto a admitirlo cuando a su llegada se reúnan en estos las condiciones adecuadas de acogida y asistencia para el menor, en función de sus necesidades». El apartado 2. ${ }^{\circ}$ del artículo 5 de la Resolución de 1997 establece que «mientras no sea posible realizar la repatriación en dichas condiciones, los Estados miembros deberían en principio dar la posibilidad de que el menor permanezca en su territorio». Por último, cabe destacar que la Resolución de 1997 subraya la importancia de la reagrupación familiar. Por eso, insta a los Estados miembros a localizar a la familia del menor no acompañado. Según el apartado 3. ${ }^{\circ}$ del artículo 3, los Estados miembros «deberían procurar encontrar lo antes posible a la familia del menor no acompañado, o localizar el lugar de residencia de sus familiares, independientemente del estatuto jurídico de los mismos» (art. 3.3).

A pesar de la importancia de la Resolución de 1997, no obstante, no contiene «una garantía suficiente para la salvaguarda de los derechos de los menores no acompañados $\rangle^{48}$. De hecho, la Resolución incluye diversas normas severas respecto a la entrada de los menores al territorio a los Estados miembros. Asimismo, la Resolución permite a los Estados miembros denegar la admisión de la entrada si los menores no llevan los documentos y las autorizaciones requeridas para ello, salvo si solicitan el asilo (art. 2.1). En este punto último, la Resolución distingue entre los menores solicitantes de asilo o no. Por último, la Resolución no actúa bien cuando permite a las autoridades de un Estado miembro que los menores permanezcan en la frontera, hasta que se dicte una resolución sobre su admisión al territorio o sobre su retorno. Aparte de que la Resolución europea de 1997 no contiene garantías suficientes para la salvaguarda de los derechos de los menores no acompañados, la Resolución europea no tiene fuerza vinculante para los Estados miembros. Díez Morrás señala que la Resolución de 1997 «no tiene fuerza vinculante, por lo que minora su efectividad ${ }^{49}$. En la misma línea Senovilla Hernández afirma que los Estados miembros no

\footnotetext{
48 SENOVILLA HERNÁNDEZ, D., «Situación y tratamiento de los menores extranjeros no acompañados en Europa», ob. cit., p. 11 y p. 23.

49 DÍEZ MORRÁS. J., «Indefinición del interés superior del menor extranjero no acompañado en perjuicio de su protección», Protección Jurídica, responsabilidad penal y mediación en justicia de menores, REDUR, Universidad de Rioja, Logroño, 2012, pp. 95-104.
} 
están obligados a aplicar las normas de la Resolución de 1997 sino que «deberían tenerlas en cuenta y esforzarse en incorporarlas a su Derecho interno» ${ }^{50}$.

Debido a la falta de garantías previstas en la Resolución de 1997, el Parlamento y el Consejo europeo han decretado otras resoluciones para reforzar las medidas de protección a los menores que se encuentran en la UE. Entre las resoluciones más importantes se destaca:

a) Resolución de 15 de abril de 2011 de la Asamblea Parlamentaria del Consejo de Europa: sobre los problemas relacionados con la llegada, estancia, y regreso de menores no acompañados en Europa.

b) Resolución del Parlamento Europeo del 12 de septiembre de 2013: sobre la situación de los menores no acompañados en la Unión Europea.

c) Resolución de 13 octubre de 2016 de la Asamblea Parlamentaria del Consejo de Europa: cuyo objeto es armonizar la protección de los menores no acompañados en Europa.

El tercer documento que el estudio va a tratar es la Comunicación de la Comisión Europea al Parlamento Europeo y al Consejo en 12 de abril de 2017.

\section{Comunicación de la Comisión Europea al Parlamento y al Consejo de Europa}

El 12 de abril de 2017 la Comisión Europea aclaró en una comunicación dirigida al Parlamento Europeo y al Consejo las medidas que debe adoptar por la Unión Europea para dar respuesta a las urgentes carencias en la protección de los menores no acompañados, y a las necesidades a las que estos se enfrentan una vez llegan a Europa ${ }^{51}$. Sin entrar en los detalles de la comunicación, las medidas tomadas por la Comisión Europea se han centrado en las siguientes materias:

1) Proteger a los menores en las rutas migratorias y poner en marcha proyectos orientados a garantizar un entorno seguro para los menores en la ruta migratoria. Según la Comisión Europea la migración ilegal de menores no acompañados a la UE a través de rutas peligrosas los expone a la trata de menores y a la explotación, y pone su salud y su vida en riesgo ${ }^{52}$.

2) Identificación y protección rápida y completa. La Comisión propone que los menores migrantes que entran a un Estado miembro deben ser identificados y registrados como menores. Además, los menores deben gozar de prioridad en todos

50 SENOVILLA HERNÁNDEZ, D., «Situación y tratamiento de los menores extranjeros no acompañados en Europa», ob. cit., p. 11 y p. 23.

51 SENOVILLA HERNÁNDEZ, D., «Situación y tratamiento de los menores extranjeros no acompañados en Europa», ob. cit., p. 5.

$52 \quad$ Ibid, p. 3. 
los procedimientos relacionados con las fronteras y recibir un apoyo adecuado por parte de personal especializado en el proceso de identificación y registro, prestando especial atención a la recuperación de la documentación pérdida ${ }^{53}$.

3) La localización de las familias y su reunificación. Según las directrices de la Comisión los procesos transfronterizos de localización y reunificación de familias deben ser más fluidos y rápidos para todos los menores, ya soliciten la protección internacional o no, y puedan, por tanto, optar a ser trasladados en aplicación del Reglamento de Dublín o en virtud de la Directiva de reagrupación familiar, cuando proceda ${ }^{54}$.

4) Acogida de menores migrantes en la UE. La Comisión ha aclarado que «las condiciones de acogida para menores migrantes incluyen no solo un alojamiento seguro y apropiado, sino también todos los servicios de apoyo necesarios para garantizar el interés superior del menor y su bienestar, como por ejemplo, una representación independiente, acceso a educación, sanidad, apoyo psicosocial, actividades de ocio y medidas relacionadas con la integración $»^{55}$.

5) La protección por el asilo. En caso de los solicitantes de asilo la Comisión aclara que se debe otorgar prioridad a los menores no acompañados y separados ${ }^{56}$.

Junto a las directrices citadas, la Comisión Europea en su comunicación al Parlamento Europeo y al Consejo adoptó otras medidas cautelares en caso de los menores no acompañados desaparecidos en el territorio de la UE. En la tercera parte de este estudio aclaramos estas medidas.

Se puede decir que las medidas tomadas por la Comisión Europea han abordado de manera mucho mejor la situación de los menores no acompañados, en comparación con la Resolución de 1997. No obstante, es necesario decretar nuevas resoluciones de carácter vinculante para los Estados miembros, de modo que aseguren un ejercicio eficaz de los derechos de los menores no acompañados que se encuentran en la Unión Europea. Además, los Estados europeos deben tener en cuenta el interés superior del menor, como principio básico en los convenios internacionales y comunitarios. Díez Morrás señala que «la regulación comunitaria hoy existente referida a los menores extranjeros no acompañados es exigua y no concreta ni da contenido satisfactorio al concepto jurídico del "interés superior del menor" $\gg^{57}$. En síntesis, a la hora de tomar medidas de protección es necesario

53 SENOVILLA HERNÁNDEZ, D., «Situación y tratamiento de los menores extranjeros no acompañados en Europa», ob. cit., pp. 6-7.

54 Comunicación de la Comisión al Parlamento Europeo y al Consejo, Protección de los menores migrantes, ob. cit., p. 7.

55 Comunicación de la Comisión al Parlamento Europeo y al Consejo, Protección de los menores migrantes, ob. cit., p. 8 .

56 Comunicación de la Comisión al Parlamento Europeo y al Consejo, Protección de los menores migrantes, ob. cit., p. 11 .

57 DÍEZ MORRÁS. J., «Indefinición del interés superior del menor extranjero no acompañado en perjuicio de su protección», ob. cit,cit., p. 100. 
que los Estados miembros valoren si las medidas adoptadas respetan el principio del interés superior del menor.

En la tercera parte de este estudio tratamos de explicar la situación actual de los menores refugiados sirios, luego, ofrecemos algunas de las medidas de protección que podrían resolver la situación vulnerable de los menores refugiados sirios.

\section{SITUACIÓN ACTUAL DE LOS MENORES REFUGIADOS SIRIOS: UNA GENERACIÓN PERDIDA}

Comenzamos esta parte del estudio con unas preguntas: ¿qué futuro les espera a los niños y niñas de Siria? ¿El refugio de los menores sirios en los países vecinos de Siria, y en los Estados europeos, podría otorgarles la oportunidad de construir un nuevo futuro?

En realidad, para responder a las preguntas planteadas es necesario realizar un estudio detallado que abarcase a todos los Estados regionales e internacionales que recibieron a los sirios y sus hijos. Sin embargo, ofrecemos en las siguientes líneas algunos de los datos más llamativos sobre la situación actual de los niños sirios, dentro y fuera de su país.

\section{Los niños sirios constituyen la parte más afectada por la guerra siria}

No cabe duda de que la guerra en Siria representa una de las crisis humanitarias más duras y horribles en el siglo XXI. Sus catastróficas consecuencias se excedieron del ámbito regional para pasar al ámbito internacional. A partir del año 2012 miles de personas de nacionalidad siria cruzaron las fronteras en busca de un lugar más seguro. Son diversos los países donde los sirios se han refugiado, siendo Turquía el país en el que más se ha acogido la población siria, cerca de 4 millones de personas, entre los cuales un millón y medio son niños $^{58}$. La UNICEF estima que 8.4 millones de niños se han visto afectados por el conflicto sirio $^{59}$. Las cifras indican que casi el $40 \%$ están sin escolarizar, «lo que aumenta la posibilidad de que se conviertan en víctimas del trabajo infantil o de un matrimonio prematuro ${ }^{60}$. Según la fundación Save The Children, uno de cada tres niños sirios no está escolarizado, con lo que indica que al menos 2.7 millones de niños no van a la escuela, ya sea dentro o

58 KEMAL KIRISCI., Turquía alberga a 3.6 millones de refugiados de la guerra en Siria. Disponible en: $<$ https://www.semana.com/contenidos-editoriales/turquia-el-peso-de-la-historia/articulo/turquia-alberga-a-36millones-de-refugiados-de-la-guerra-en-siria/596247>. [Consultado el 12/01/2019].

59 UNICEF México, «5 años de crisis en Siria: 1 de cada 3 niños sirios solo ha vivido en situación de conflicto desde su nacimiento». Disponible en: $<$ https://www.unicef.org/mexico/spanish/noticias_32555.html $>$. [Consultado el 12/11/2017].

60 Unicef y la UE aúnan fuerzas para escolarizar a los niños sirios refugiados en Turquía, artículo publicado en EuroNews. Disponible en $<$ https://es.euronews.com/2018/05/31/unicef-y-la-ue-aunan-fuerzas-para-escolarizara-los-ninos-sirios-refugiados-en $>$. [Consultado el 01/10/2018]. 
fuera del país ${ }^{61}$. Actualmente, miles de niños sirios se encuentran en situaciones trágicas en los Estados vecinos de Siria, (en Jordania y Líbano). Debido a la pobreza y también la carencia de los recursos económicos aportados por las autoridades jordanas y libanesas a los refugiados sirios, muchos niños trabajan para poder ayudar a sus familias. El Sr. Lake, director ejecutivo de la UNICEF, ha resumido la situación de los niños sirios en una declaración diciendo: «estamos realmente ante una generación pérdida» ${ }^{62}$.

Desde el cierre de las fronteras de los países europeos del Este y los Balcanes ante la migración de $\operatorname{los} \operatorname{sirios}^{63}$, muchas familias se han separado de sus hijos, así muchos de los niños sirios entraron a Europa sin la compañía de sus familias. En efecto, existen diversos datos oficiales que llaman la atención respecto a la situación de los menores sirios llegados a Europa. La fundación Save The Children estima que 26.000 niños refugiados entraron a la Comunidad Europea sin acompañantes de su familia ${ }^{64}$. Mientras que otro dato más importante indica que casi 90.000 menores llegaron a Europa en el año $2015^{65}$. El total de los menores que han cruzado las fronteras europeas, según la fundación Save The Children, alcanzaron $270.000^{66}$.

Una de las consecuencias más dolorosas del refugio de las familias sirias llegadas a Europa ha sido la desaparición de 10.000 niños. Entre los años 2015 y 2016, según los informes de EUROPOL (Unidad de lucha contra la delincuencia en la Unión Europea), 10.000 niños refugiados desparecieron tras llegar a Europa ${ }^{67}$. De acuerdo con las investigaciones de EUROPOL la pista de la mitad del total de niños desaparecidos se ha perdido en Suecia, Italia y Grecia ${ }^{68}$. La agencia policial europea recela de que los menores podrían estar

\footnotetext{
61 Euronews, «Uno de cada tres niños sirios no está escolarizado», Disponible en: <https:/es.euronews. com/2018/04/24/uno-de-cada-tres-ninos-sirios-no-esta-escolarizado $>$. [Consultado el 01/10/2018].

62 LAKE, A., «Informe sobre la crisis en Siria desde el 2011 hasta 2016: No es lugar para niños», UNICEF Siria, A displaced boy in East Ghouta Rural Damscus, Siria, 2016.

63 AMADOR, MARTA, «La respuesta europea a la crisis migratoria siria, Refugiados y desplazados en el mundo», Plan de acogida al Refugiado de UCM d + I; UNICEF ACNUR: España, 2015: El año de la crisis de refugiados en Europa. Disponible en <https:/www.ucm.es/data/cont/media/www/pag-91729/1-17\%20 Respuesta-europea-crisis-migratoria_MartaAmador.pdf $>$. [Consultado el 28/08/2019].

64 Blastingnews, «Desaparecidos 10.000 niños refugiados en Europa». Disponible en: <https:// es.blastingnews.com/internacionales/2016/02/desaparecidos-10-000-ninos-refugiados-en-europa-00759577. html>. [Consultado el 30/07/2018].

65 MERRIMAN, H., ¿Por qué hay más de 10.000 niños desaparecidos en Europa?, artículo publicado en el BBC, disponible en: <https://www.bbc.com/mundo/noticias-internacional-37649395>, [Consultado el 30/07/2018].

66 «Al menos 10.000 niños refugiados han desparecido nada más llegar a Europa», artículo publicado en el diario del Mundo Disponible en: <http://www.elmundo.es/internacional/2016/01/31/56addb6f268e3ea131 8b459e.html>. [Consultado el 03/09/2018].

${ }^{67}$ Blastingnews, «Desaparecidos 10.000 niños refugiados en Europa», ob. cit.

${ }_{68}$ Al menos 10.000 niños refugiados han desparecido nada más llegar a Europa, op.cit., [Consultado el 03/09/2018].
} 
esclavizados por mafias de explotación sexual ${ }^{69}$. También en España en el año 2016 abandonaron los servicios de protección y figuran «en fuga» 825 menores, de los que se ignora su paradero actual ${ }^{70}$. Mientras que, en 2018 desaparecieron unos 3.500 niños refugiados, pero esta vez en Alemania. En el 24 de diciembre de 2018, la Oficina de Investigación Criminal Germana (BKA) ha anunciado que hay más de 11.000 personas desaparecidas, entre ellas 7.000 menores de edad, de los cuales unos 3.500 menores refugiados. Según la BKA la mitad de los menores son niños refugiados que llegaron a Alemania sin acompañante ${ }^{71}$.

Debido a esto, la Comisión Europea en su comunicación al Parlamento Europeo y al Consejo en 12 de abril de 2017, adoptó medidas especiales. Por un lado, los menores desaparecidos encontrados en cualquier lugar del territorio de la UE han de ser identificados, registrados y derivados a las autoridades de protección de menores con celeridad ${ }^{72}$. Por otro lado, «los administradores de los centros de acogida, en particular, así como otras personas implicadas en el cuidado de menores han de informar de los casos de menores desaparecidos a la policía». Por último, «todos los casos de menores no acompañados desaparecidos han de ser registrados por la policía, que debe alertar sobre la desaparición en el Sistema de Información de Schengen (SIS) y mantenerse en contacto con la oficina nacional SIRENE. Los Estados miembros deben también solicitar que se dicte una orden de Interpol sobre personas desaparecidas, haciendo que también participe cuando proceda, Interpol» ${ }^{73}$.

A pesar de la importancia de las medidas de protección tomadas por las organizaciones de las Naciones Unidas y los Estados miembros respecto a los menores refugiados sirios, estas medidas no han podido cubrir todas las necesidades de los niños sirios y salvaguardar sus derechos como grupo vulnerable. La desaparición de miles de niños llegados a Europa, desde el 2015 hasta 2018, exige reconsiderar en los métodos adoptados por las organizaciones internacionales y los Estados miembros. La colocación de los niños no acompañados en centros de acogida y/o hogares de guarda no garantiza la protección efectiva de los MENAS. Es necesario tomar otras medidas y soluciones prácticas, en consonancia con el Derecho internacional y los convenios internacionales.

69 Desaparecen 10 mil niños refugiados y Europa los ignora, artículo publicado en telesurtv.net. Disponible en: <https:/www.telesurtv.net/news/Desaparecieron-10-mil-ninos-refugiados-y-Europa-losignora-20161029-0030.html $>$. [Consultado el 03/10/2018].

70 Save The Children: España registra 12.500 menores migrantes no acompañados en 2017, p.21. Disponible en: $<$ https://www.savethechildren.es/notasprensa/espana-registro-2500-menores-migrantes-no-acompanadosen-2017-un-604-mas-que-el-ano>. [Consultado el 09/01/2019].

71 Europapress, «En Alemania hay más de 11.000 personas desaparecidas, incluidos unos 3.500 menores refugiados». Disponible en: <https://www.europapress.es/internacional/noticia-alemania-hay-mas-11000personas-desaparecidas-incluidos-3500-menores-refugiados-20181224111441.html>. [Consultado el 28/12/2018].

72 Comunicación de la Comisión al Parlamento Europeo y al Consejo, Protección de los menores migrantes, ob. cit., p. 7.

73 Ibid, p. 8. 
En las próximas líneas se realiza una valoración de las medidas de protección que podrían resolver la situación vulnerable de los menores refugiados sirios y otros grupos de MENAS.

\section{Medidas de protección en caso de los menores refugiados sirios}

Los niños que se separan con carácter provisional o permanente de su entorno familiar tienen derecho a obtener una protección especial de los Estados y las organizaciones internacionales. Entre las medidas previstas en el ámbito del Derecho internacional, está el asilo.

\section{A. El asilo}

Según la fundación ACNUR «los menores no acompañados pueden haber solicitado asilo por miedo a la persecución, a la falta de protección ante violaciones de derechos humanos, conflictos armados y/o graves disturbios en su país de origen» ${ }^{74}$. De este modo, los niños sirios que se encuentran en un país europeo podrían solicitar el asilo debido al conflicto armado ocurrido en su país. Tanto la Convención sobre los Derechos del niño de 1989, como la Resolución del Consejo de 26 de junio de 1997 reconocen a los menores no acompañados nacionales de países terceros el derecho a solicitar el asilo. La Convención sobre los Derechos del niño dispone en el art. 22.1 que «los Estados Partes adoptarán medidas adecuadas para lograr que el niño que trate de obtener el estatuto de refugiado o que sea considerado refugiado de conformidad con el derecho y los procedimientos internacionales o internos aplicables reciba, tanto si está solo como si está acompañado de sus padres o de cualquier otra persona, la protección y la asistencia humanitaria adecuadas para el disfrute de los derechos pertinentes enunciados en la presente Convención y en otros instrumentos internacionales de derechos humanos o de carácter humanitario en que dichos Estados sean partes». También la Resolución del Consejo de 1997 prevé en su art. 4.1 que «todos los menores no acompañados deberían tener derecho a solicitar asilo». No obstante, la Resolución del Consejo de 1997 determina una serie de requisitos para poder solicitar el asilo, entre ellos, que el menor debe presentar un justificante de su edad. Si el menor no tuviera dicho justificante, en este caso los Estados miembros podrían comprobar de su edad mediante una prueba médica realizada por personal médico cualificado (art. 4.3).

De conformidad con los textos citados, los niños sirios tienen derecho a solicitar el asilo debido al conflicto armado ocurrido en su país, tanto si están solos como si están acompañados de sus padres o de cualquier otra persona. No obstante, si los niños sirios no llevan un documento de identidad oficial que acredite su nacionalidad y su edad, las autoridades no les permiten acceder al sistema de la protección de menores. La falta de un documento

\footnotetext{
74 Alto Comisionado de las Naciones Unidas para los Refugiados (ACNUR), «Guía y procesos en la atención a niños sin acompañantes solicitantes de asilo», ob. cit., 1997.
} 
oficial que acredita la identidad de estos menores se considera una de las mayores dificultades que enfrentan los países europeos respecto a la protección de los menores sirios no acompañados. Cabe destacar que la Unión Europea, en el año 2015 registró cerca de 88.300 solicitudes de asilo de menores no acompañados. En comparación con el año 2014 en el que plantearon 23.000 de solicitudes de protección internacional ${ }^{75}$.

\section{B. La reagrupación familiar}

La reagrupación familiar representa una de las medidas más importantes y efectivas para la protección a los menores no acompañados. El preámbulo de la Convención sobre los Derechos del niño de 1989 afirma el papel fundamental de la familia en el crecimiento y el bienestar del niño. Asimismo, la Convención insiste en que el niño deba crecer en el seno de una familia estable que le otorgue la protección y la asistencia necesaria para su desarrollo. El art. 10 de la Convención sobre los Derechos del niño, apartado $1 .^{\circ}$, dispone que toda solicitud presentada por el niño o sus padres para entrar o salir de un Estado miembro a efectos de la reagrupación familiar, debe ser atendida por los Estados Partes de forma positiva y humanitaria, salvo si afectase de forma negativa al niño ${ }^{76}$. En caso de que los padres del niño residan en diferentes países, el niño tiene derecho a mantener periódicamente relaciones personales y contactos directos con ambos padres. También el apartado $2 .^{\circ}$ del art. 22 de la Convención establece que los Estados Partes cooperarán con las organizaciones para ayudar a todo niño refugiado a localizar a sus padres, o a otros miembros de su familia. Conforme al apartado 2. ${ }^{\circ}$ del artículo 22: «A tal efecto los Estados Partes cooperarán, en la forma que estimen apropiada, en todos los esfuerzos de las Naciones Unidas y demás organizaciones intergubernamentales competentes $u$ organizaciones no gubernamentales que cooperen con las Naciones Unidas por proteger y ayudar a todo niño refugiado y localizar a sus padres o a otros miembros de su familia, con el fin de obtener la información necesaria para que se reúna con su familia». Por su parte, la Resolución del Consejo de 26 de junio de 1997 establece que los Estados miembros, independientemente del estatuto jurídico de los menores, «deberían procurar encontrar lo antes posible a la familia del menor no acompañado, o localizar el lugar de residencia de sus familiares» (Art. 3.3).

A la luz de los textos citados, los Estados Partes de las convenciones internacionales deben localizar el lugar de residencia de la familia de los niños refugiados sirios. En las situaciones en que no se pueda localizar a ninguno de los padres o miembros de la familia del menor, el apartado $2 .^{\circ}$ del artículo 22 de la convención de 1989, prevé que «el menor tendrá derecho a la misma protección que cualquier otro niño privado permanente o temporalmente de su medio familiar, por cualquier motivo». No obstante, si los niños sirios no llevan un

75 REQUEJO ISIDRO, M., «La protección del menor no acompañado solicitante de Asilo: Entre Estado competente y Estado responsable», ob. cit., p. 483.

${ }_{76}$ ARCE FERNÁNDEZ, I., Cuaderno Recopilatorio de Legislación Relativa a Menores de Edad, ob. cit., p. 76.

RJUAM, n. ${ }^{\circ}$ 39, 2019-I, pp. 9-43

ISSN: 1575-720-X 
documento de identidad oficial que acredite su nacionalidad, se hace difícil la localización de su familia en el área europea y por lo tanto su devolución a ella. Si los Estados y las organizaciones de las Naciones Unidas no pueden localizar a la familia del menor deben emplear otras medidas efectivas, así como la integración de los menores refugiados sirios en otras familias que pertenecen a su origen cultural.

\section{Integración de los menores sirios en familias que pertenecen a su origen cultural}

La integración a los menores sirios no acompañados en otras familias que pertenecen a su origen cultural o bien similar, como, por ejemplo, familias marroquíes o argelinas que residen en España es una buena solución, si tenemos en cuenta las normas de las Convenciones internacionales. El apartado 3. ${ }^{\circ}$ del artículo 20 de la Convención sobre los Derechos del niño dispone que «al considerar las soluciones, se prestará particular atención a la conveniencia de que haya continuidad en la educación del niño y a su origen étnico, religioso, cultural y lingüístico». De este modo, las instituciones internacionales en la intervención de la protección de los menores sirios deben tener en cuenta los factores sociales y culturales de la procedencia de los menores. Así pues, las administraciones responsables de los menores en algunas de las Comunidades Autónomas (CCAA) de España han aplicado este método en caso de los menores marroquíes no acompañados y ha dado buenos resultados ${ }^{77}$. Entre las CCAA que han aplicado esta medida está la Comunidad Andaluza en su «Programa de Acogimiento Familiar de Menores $\rangle^{78}$. Por lo tanto, se puede aplicar perfectamente esta medida en el caso de los MENAS sirios. La integración de los menores en otro ambiente familiar distinto de su cultura no satisface las necesidades emocionales y socioeducativas de estos menores, probablemente podría causar una situación de desprotección.

\section{La protección de los menores no acompañados mediante la institución de la Kafala}

A pesar de la prohibición de la adopción en el Corán (versículos 4 y 5 de la Sura 33 del Corán) $)^{79}$, la legislación musulmana no ignora la existencia de muchos niños huérfanos $\mathrm{y}$ abandonados que necesitan el cuidado y la protección por parte de la sociedad ${ }^{80}$. En el

77 BRAVO RODRÍGUEZ, Ma ., La situación de menores no acompañados en España, ob.cit., p.22.

78 RAMÍREZ FERNÁNDEZ, A; JIMÉNEZ ÁLVAREZ. M., (coords.), Las otras migraciones: La emigración de menores marroquies no acompañados, Madrid (Universidad Internacional de Andalucía, Akal), 2005, p.236.

79 De entre los textos del Corán que prohíben la adopción se menciona: [Es más justo ante Allah que (a vuestros hijos adoptivos) los llaméis con los nombres de sus padres, pero si no conocierais a sus padres, son vuestros hermanos en la Creencia y vuestros allegados], el Corán, Sura 33, versículos 4 y 5 . El Corán indica de forma clara que los hijos son aquellos que nacen de las esposas: [Y Allah os ha dado esposas, y de las cuales hijos y nietos], el Corán, Sura 16, versículo 72. El Noble Corán, traducción y comentario por Abdel Ghani Melara Nvaio, disponible en: $<$ http://noblecoran.com/index.php/coran-traducido/traduccion-de-abdel-ghanimelara $>$.

80 SÁNCHEZ CANO, Ma ., «Adopción en España de menores en situación de Kafala y Ley nacional del adoptando», Cuadernos de Derecho Transnacional, vol. 10, n. ${ }^{\circ}$ 2, 2018, p.931; ORTEGA GIMÉNEZ, A., 
Derecho musulmán ${ }^{81}$ existe otra institución jurídica que aporta la protección a cualquier niño abandonado o huérfano, de modo que la familia acogedora asume todos los gastos del niño. Esto es, lo que comprende alimentarlo y cuidarlo a costa suya hasta que aparezcan sus padres. Esta institución se conoce por el nombre de Kafala. La concepción de la Kafala consiste en que «todas las personas de la comunidad, ya sean individuos como grupos, gobernantes o gobernados, deben tomar actitudes positivas tales como el cuidado de los huérfanos y abandonados» ${ }^{82}$.

En su condición como medida protectora al menor, la Kafala es contemplada en la mayoría de los Convenios internacionales de Derecho internacional, tanto público como de contenido de Derecho internacional privado. Así, el apartado 3..$^{\circ}$ del artículo 20 de la Convención sobre los Derechos del niño se refiere de forma clara a la Kafala. En virtud del artículo 20: «entre esos cuidados figurarán, entre otros aspectos, la colocación en hogares de guarda, la Kafala del Derecho islámico, la adopción o de ser necesario, la colocación en instituciones adecuadas de protección de menores». También los arts. 3 y 33 del Convenio de La Haya de 19 de octubre de 1996 aluden a la institución de la Kafala entre las medidas de la protección al menor. Conforme a su artículo 3, es posible «la colocación del niño en una familia de acogida o en un establecimiento, o su protección legal mediante Kafala».

Desde el punto de vista jurídico, la Kafala establecida por la Ley marroquí n. ${ }^{\circ} 15$ de 13 de junio de $2002^{83}$, es una institución reconocida por los ordenamientos europeos, como en el caso de España. El Derecho español reconoce la Kafala como medida de protección al menor asimilada al sistema del acogimiento familiar o tutela ${ }^{84}$. El apartado $1 .^{\circ}$ del artículo 34 de la Ley 54/2007 de 28 de diciembre, de Adopción Internacional (en lo sucesivo LAI), modificado por la Ley 26/2015 de Protección del Menor de la Infancia y de la Adolescencia $^{85}$, dispone que «las instituciones de protección de menores constituidas por autoridad extranjera y que, según la ley de su constitución, no determinen ningún vínculo de filiación se equiparán al acogimiento familiar o, en su caso, a una tutela». En los siguientes apartados del mismo artículo la ley española determina los requisitos que deben cumplirse para reconocer los efectos legales de la Kafala. Asimismo, la Resolución-Circular de la DGRN

«La Kafala de Derecho Islámico: Concepto, Naturaleza Jurídica, Caracteres y Efectos Jurídicos en España», Actualidad Jurídica Iberoamericana, n. ${ }^{\circ}$ 3, 2015, pp. 819-826.

81 El Derecho musulmán es un término se refiere a dos disciplinas: la Sharia y el Figh. La Sharia abarca las disposiciones expresadas claramente en los textos del Corán y la Sunna. Mientras que, el Fiqh incluye todas las disposiciones y también las fetuas deducidas por los juristas musulmanes de los textos del Corán y la Sunna mediante el razonamiento lógico.

82 ABDEL ALLAH, ALWAN., La solidaridad social en el Islam, Cairo (Dar Asslam), 2007, p. 9.

83 La Kafala en la Ley marroquí n 15 de 13 de junio de 2002. Disponible en: $<$ http://www.amicsinfantsmarroc. org/kafala.es.php>.

84 RODRÍGUEZ PINEAU, E., «La protección en España de menores cuya ley nacional prohíbe la adopción tras la reforma de la Ley 54/2007 de Adopción Internacional», Derecho Privado y Constitución, n. ${ }^{\circ}$ 31, 2017, p.390.

85 BOE núm. 180, de 29/07/2015, Ley 26/2015, de 28 de julio, de modificación del sistema de protección a la Infancia y Adolescencia. 
de 15 de julio de 2006, no descarta la eficacia de las Kafalas en España ${ }^{86}$, si han sido válidamente constituidas por autoridad extranjera, siempre que no vulneran el orden público internacional español y si los documentos en los que constan se presentan debidamente legalizados y traducidos a idioma oficial español ${ }^{87}$.

A pesar de que el Derecho español reconoce la institución de la Kafala como medida protectora al menor, los ciudadanos españoles no podrían constituir una Kafala si no residen en Marruecos. Según las nuevas condiciones de la Circular n. ${ }^{\circ} 40 \mathrm{~S} / 2$ decretada por el Ministro de Justicia y Libertad marroquí, «el solicitante extranjero debe tener su residencia habitual en Marruecos». El motivo de la modificación de las condiciones de la Kafala por las autoridades marroquíes es el cambio del estatuto jurídico del niño de la institución de la Kafala a la adopción, prohibida en el Derecho de familia marroquí ${ }^{88}$. Ante la constitución de Kafalas fraudulentas, el gobierno español ha introducido algunas modificaciones a la Ley de Adopción Internacional (LAI).

Con la modificación introducida en LAI, en su artículo19, las solicitudes de adopción de menores procedentes de países musulmanes ya no son reconocidas por el Derecho español. En virtud del artículo 19 apartado 4..$^{\circ}$ : «en el caso de menores cuya ley nacional prohíba o no contemple la adopción se denegará la constitución de la adopción, excepto cuando el menor se encuentre en situación de desamparo y tutelado por la Entidad Pública». El motivo, como explican diversos juristas ${ }^{89}$, es impedir la constitución en España de adopciones claudicantes después de haberse decretado una Kafala en el Estado de origen del menor, en tanto que «atentan gravemente a la seguridad jurídica del menor» ${ }^{90}$.

Ahora bien, la prohibición de la adopción de niños musulmanes podría no operar, como señala el epígrafe segundo del art. 19.4, esto es «cuando el menor se encuentre en situación de desamparo y tutelado por la Entidad pública». A la luz del texto anterior, los niños refugiados sirios que se encuentran en el territorio español podrían ser adoptados por nacionales españoles, si se cumplen las condiciones citadas arriba, esto es, que estén en situación de desamparo y tutelados por la Entidad pública.

Si las condiciones del art. 19.4 no se cumplan, los ciudadanos españoles podrían recurrir a la institución de la Kafala como medida de protección al menor, asimilada al sistema del acogimiento familiar o tutela, tal como dispone el art. 34.1 de la Ley de Adopción Inter-

86 BOE núm. 207 de 30 de agosto de 2006, Resolución-Circular de la DGRN de 15 de julio de 2006.

87 Resolución-Circular de la DGRN de 15 de julio de 2006, los requisitos exigidos por el Código Civil español para el reconocimiento de las adopciones internacionales, véase los párrafos: Cuarto y Quinto.

88 SÁNCHEZ CANO, M‥, Adopción en España de menores en situación de Kafala y Ley nacional del adoptando, op.cit., p.932.

89 SÁNCHEZ CANO, M‥, Adopción en España de menores en situación de Kafala y Ley nacional del adoptando, ob. cit., p. 933; RODRÍGUEZ PINEAU, E., La protección en España de menores cuya ley nacional prohibe la adopción tras la reforma de la Ley 54/2007, de Adopción Internacional, ob. cit., p. 390.

90 RODRÍGUEZ PINEAU, E., La protección en España de menores cuya ley nacional prohíbe la adopción tras la reforma de la Ley 54/2007, de Adopción Internacional, ob. cit., p. 390. 
nacional, si tienen su residencia habitual en Marruecos en virtud de la Circular n. ${ }^{\circ} 40 \mathrm{~S} / 2$. En este caso, los cuidadores no pueden cambiar el estatuto jurídico del menor de la institución de la Kafala a la adopción, puesto que sería denegada por el Derecho español conforme al art. 19.1 de la Ley 26/2015 de Protección del Menor, de la Infancia y de la Adolescencia.

\section{E. El retorno de los menores sirios no acompañados a su país}

Según el apartado $1 .^{\circ}$ del art. 5 de la Resolución del Consejo de 26 de junio de 1997, el retorno de los menores será posible cuando se reúnen en el país de origen del menor todas las condiciones apropiadas para su acogida y asistencia, «teniendo en cuenta las necesidades especiales del menor, su edad y su nivel de autonomía». El apartado 2. ${ }^{\circ}$ del artículo 5 de la Resolución de 1997 prevé que «mientras no sea posible realizar la repatriación en dichas condiciones, los Estados miembros deberían en principio dar la posibilidad de que el menor permanezca en su territorio».

En las situaciones actuales en Siria, es cierto que esta medida no es adecuada en cuanto a los menores sirios. Las condiciones a las que se refiere el artículo 5 de la Resolución de 1997, no se cumplen en Siria. El país tras 8 años de guerra sigue estando en la misma condición. Las infraestructuras del agua y la luz están dañadas totalmente en diversas partes del país, los colegios están destruidos y faltan profesores y medios de educación, además el país sigue sufriendo necesidades de alimentación y medicina según muchos informes de la $\mathrm{ONU}^{91}$. Por último, según el índice de Paz Global (GPI) publicado por el Institute for Economics and Peace en el $2018^{92}$, Siria es el país más peligroso del mundo para vivir, colocándose en la última posición de la clasificación. Por todas las razones anteriores no será posible realizar la repatriación de los menores sirios a su país. Los Estados miembros deberían en principio dar la posibilidad de que los MENAS sirios permanezcan en su territorio, tal como dispone el apartado 2. ${ }^{\circ}$ del artículo 5 de la Resolución de 1997, hasta que mejore la situación en Siria y que les permita un regreso voluntario a su país en condiciones de seguridad y dignidad.

\section{F. Firmar un acuerdo con el gobierno sirio}

Al igual que los acuerdos firmados entre España y Marruecos y también Senegal, es necesario firmar un acuerdo con el gobierno sirio. Aunque Siria ha ratificado la Convención sobre los Derechos del niño en el año 1993, no forma parte de muchos convenios internacionales sobre la protección de los menores. La Ley Orgánica de 2/2009 (Reforma de la Ley 4/2000) sobre derechos y libertades de los extranjeros en España, dispone en su artículo 35,

\footnotetext{
${ }_{91}$ Los niños de Siria ni siquiera conocen el significado de la palabra paz. Disponible en: $<$ https://news. un.org/es/focus/siria>. [Consultado el 20/10/2018].

${ }_{92}$ Estos son los países más peligrosos del mundo: ranking 2018, artículo publicado en Conocedores. Disponible en: $<$ https://conocedores.com/estos-son-los-paises-mas-peligros-del-mundo-ranking-2018-16550 $>$. [Consultado el 28/12/2018].
} 
apartado $1^{\circ}$, que «el gobierno promoverá el establecimiento de acuerdos de colaboración con los países de origen que contemplen, íntegramente, la prevención de la inmigración irregular, la protección y el retorno de los menores no acompañados». De este modo, el Estado español y los demás países europeos podrían firmar acuerdos de cooperación con el gobierno sirio. El objetivo sería establecer el marco jurídico adecuado que resolviese la situación de los menores sirios no acompañados que se encuentren en los Estados miembros de la UE. Entre los aspectos que los acuerdos se destacarían: la localización de los padres de los niños sirios u otros miembros de su familia, y su retorno a su país en el futuro cuando mejore la situación allí.

\section{COMPETENCIA JUDICIAL INTERNACIONAL Y LA LEY APLICABLE EN MATERIA DE PROTECCIÓN DE LOS REFUGIADOS Y DESPLAZA- DOS}

A continuación, se establecerán los aspectos de Derecho internacional privado objeto de análisis: competencia judicial internacional y, de forma posterior, la ley aplicable a las medidas de protección de los niños refugiados y desplazados.

\section{Competencia judicial internacional en materia de protección de los menores refugiados y desplazados}

Según las normas del Convenio de La Haya de $1996^{93}$, las autoridades competentes para tomar medidas de protección en caso de los niños refugiados y desplazados se corresponden con las del Estado contratante en cuyo territorio se encuentran estos niños como consecuencia de su desplazamiento ${ }^{94}$. El art. 6 del Convenio de La Haya dispone de forma clara que «para los niños refugiados y aquellos niños que, como consecuencia de desórdenes en sus respectivos países, están internacionalmente desplazados, las autoridades del Estado contratante en cuyo territorio se encuentran como consecuencia del desplazamiento, ejercen la competencia prevista en el apartado primero del artículo $5 »$.

En principio, la regla general en virtud del art. 5 del Convenio de La Haya de 1996, prevé que las autoridades del Estado contratante de la residencia habitual del niño son competentes para adoptar las medidas para la protección de su persona o sus bienes. Sin embargo, la estancia temporal de los niños refugiados y desplazados en el territorio de un Estado contratante no se considera en ningún caso como residencia habitual de estos niños. Por lo tanto, la norma general relacionada con la residencia habitual del niño no se aplica en este caso, sino que la competencia judicial se atribuye a las autoridades del Estado contra-

3 BOE núm. 291, de 2 diciembre de 2010.

94 CALVO CARAVACA, L Y CARRASCOSA GONZÁLEZ, J., Derecho Internacional Privado, ob. cit., p. 455. 
tante en cuyo territorio se encuentran los niños refugiados y desplazados, tal como dispone el art. 6 del Convenio de La Haya.

Los grupos que contiene el art. 6 son dos tipos de niños: refugiados y desplazados. Lagarde Paul aclara que «la categoría de niños aquí considerada está limitada a aquellos que se fueron de su país por las condiciones que allí reinaban, y que a menudo no están acompañados y en todo caso privados temporal o definitivamente de sus padres» ${ }^{95}$. A la luz de lo mencionado se puede afirmar que los niños sirios entran en los dos grupos a que se refiere el art. 6, refugiados y desplazados. El desplazamiento de los menores sirios a los países europeos, como hemos explicado, no ha sido una decisión planificada sino que se ha generado de forma forzosa debido a la guerra y las situaciones catastróficas en su país.

Si la residencia habitual del menor no se puede determinar, el apartado 2. ${ }^{\circ}$ del art. 6 también confiere la competencia para adoptar medidas de protección a las autoridades del Estado contratante en cuyo territorio se encuentran estos niños. En virtud del apartado 2. ${ }^{\circ}$ del art. 6 «la disposición del apartado precedente se aplica también a los niños cuya residencia habitual no puede determinarse». De este modo, si el niño abandona el centro de acogida en un Estado contratante y se desplaza a otro país europeo, en este caso, las autoridades competentes para adoptar medidas de protección son aquellas en cuyo territorio se encuentra este niño o los niños desplazados entre dos Estados europeos diferentes. No obstante, si el niño se establece en un Estado y obtiene de forma legal su residencia se volverá a aplicar la norma general del art. 5. Esto es, que las autoridades del Estado contratante de la residencia habitual del niño son competentes para adoptar las medidas para la protección de su persona o sus bienes. En definitiva, todas las normas previstas en los artículos 5 y 6 del Convenio de La Haya se aplican a los menores refugiados sirios encontrados en los Estados europeos.

\section{La ley aplicable en materia de protección de los menores refugiados y desplazados}

Respecto a la ley aplicable en materia de protección de menores, el apartado $1 .^{\circ}$ del art. 15 del Convenio de La Haya de 1996 dispone que «las autoridades de los Estados contratantes aplican su propia ley». La regla general, en virtud del art. 15.1, es que cada Estado aplicará sus normas legislativas nacionales o internas. De acuerdo con los profesores Calvo Caravaca y Carrascosa González, «los tribunales y demás autoridades que resulten internacionalmente competentes con arreglo a los foros de competencia internacional recogidos en el Convenio de La Haya de 1996, aplican siempre su propia normativa jurídica sustantiva en lo relativo a las medidas de protección de los niños ${ }^{96}$. La norma que prevé el apartado 1. ${ }^{\circ}$ del art. 15 tiene la ventaja de que las autoridades de los Estados contratantes aplicarán

\footnotetext{
LAGARDE PAUL., Conferencia de La Haya de Derecho Internacional Privado, Informe explicativo, texto adoptado por la XVIII sesión, HCCH, n. ${ }^{\circ}$ 44, La Haya, Países Bajos, 2017, p. 25.

96 CALVO CARAVACA, L Y CARRASCOSA GONZÁLEZ, J., Derecho Internacional Privado, ob. cit., p. 465 .
} 
la ley que más conocen ${ }^{97}$. En este sentido, FERNÁNDEZ PÉREZ afirma que el apartado $1 .^{\circ}$ del art. 15 «establece una regla de base caracterizada por la vinculación forum/ius, y concretada en el postulado de aplicación a las medidas de protección del menor de la lex fori (art. 15.1), un postulado que responde a que la proximidad del interés descansa en normas de competencia judicial internacional supeditadas a la residencia habitual del menor ${ }^{98}$.

La regla general prevista en el apartado $1 .^{\circ}$ del art. 15 tiene cláusula de excepción ${ }^{99}$. Según el apartado $2{ }^{\circ}$ del mismo artículo 15 es posible la aplicación de la ley de otro Estado con el que la situación tenga un vínculo estrecho. En virtud del apartado $2 .^{\circ}$ del artículo 15 «no obstante, en la medida en que la protección de la persona o de los bienes del niño lo requiera, pueden excepcionalmente aplicar o tomar en consideración la ley de otro Estado con el que la situación tenga un vínculo estrecho». De acuerdo con Herranz Ballesteros el artículo 15 «recoge una cláusula de excepción cuyo funcionamiento en este caso permite, si el interés del menor lo requiere, aplicar un ordenamiento distinto al que normalmente sería aplicable» ${ }^{100}$. A tenor de los términos del apartado $2 .^{\circ}$ del artículo 15 , las autoridades competentes pueden aplicar o bien tomar en consideración la legislación de otro Estado si consideran que la aplicación de la ley de otro Estado tiene conexiones más estrechas con el supuesto litigioso, siempre que el interés del menor lo requiere.

Así pues, si las autoridades españolas reciben solicitud de los tribunales austriacos que les permiten vender la casa, situada en Austria, de dos niños sirios refugiados en España y tutelados por la administración pública española, deberían aplicar la ley de Austria en virtud del apartado $2 .^{\circ}$ del artículo 15 y conceder la autorización para vender la casa. El motivo es que la ley austriaca tiene un vínculo más estrecho con el supuesto litigioso, es la ley del lugar de situación del bien o lex rei sitae.

La norma prevista en el apartado $2 .^{\circ}$ no se aplica sin restricciones sino que las autoridades competentes deben asegurarse de que la aplicación de la ley de otro Estado protege más al menor y toma en consideración el interés superior del niño ${ }^{101}$. En caso de que un niño sirio tenga su residencia habitual en Alemania, y que se desplace a España para realizar una operación médica urgente en un hospital español, las autoridades españolas deberían pedir autorización a las autoridades alemanas competentes para realizar la operación del niño. Si las autoridades alemanas se aseguran de que la aplicación de la ley española protege más al menor sirio que su ley nacional, estamos ante situación de urgencia, en este caso, deberían autorizar al hospital situado en España que realice la operación médica. La autorización

97 Manual práctico sobre el funcionamiento del Convenio de La Haya de 1996 sobre Protección de Niños, HCCH Hague conference on prívate international Law, Capitulo 9, La Haya, Países Bajos, 2014 , p. 91.

98 FERNÁNDEZ PÉREZ, A., «Funciones de las cláusulas de excepción en el proceso de localización de la norma de conflicto», Revista española de Derecho Internacional, vol. 67, n. o 2, 2015, p. 104.

99 HERRANZ BALLESTEROS, M., et al, Derecho Internacional Privado, Madrid (UNED), $2^{\mathrm{a}}$ ed., 2016 , p. 556 .

100 HERRANZ BALLESTEROS, M., Derecho Internacional Privado, ob. cit., p. 556.

101 LAGARDE PAUL., Conferencia de La Haya de Derecho Internacional Privado, ob. cit., p. 45. 
concedida a las autoridades españolas, como parece, está basada en el principio del interés superior del niño. En resumen, las autoridades alemanas aplicarán siempre su propia ley nacional como dispone el art. 15.1, a salvo de que concurran circunstancias necesarias o urgentes que requieran la aplicación de la ley de otro Estado con el que la situación se encuentra estrechamente conectada.

Por último, el art. 15 en su apartado $3 .^{\circ}$ trata la situación de cambio de residencia del menor a otro Estado parte del Convenio. En virtud del apartado 3. ${ }^{\circ}$ del art. 15, el cambio de residencia del menor conlleva un cambio de las autoridades competentes para adoptar medidas de protección. Sin embargo, este cambio de la residencia no afectará a las medidas adoptadas inicialmente por las autoridades según su antigua residencia, sino a las condiciones de su aplicación. Según los términos del apartado 3. ${ }^{\circ}$, la ley del Estado de la nueva residencia del menor solo se aplicará a las condiciones de las medidas adoptadas en el Estado de la anterior residencia habitual, a partir del momento en que se produce la modificación ${ }^{102}$.

Con la exposición de las normas del Convenio de La Haya de 1996, vinculada con la competencia judicial internacional y la ley aplicable en caso de los menores refugiados y desplazados llegamos al final de este trabajo. Antes de concluir nuestro estudio realizamos una valoración final de lo que ha conseguido esta investigación.

\section{CONCLUSIONES}

El refugio que buscan los menores sirios en calidad de MENAS en Europa y sus Estados miembros, a diferencia de otros grupos de MENAS, no tiene bases económicas. El desplazamiento de los menores sirios se ha generado de forma forzosa debido a la guerra y las situaciones catastróficas en su país. Es necesario tomar medidas y soluciones prácticas y seguras, en consonancia con el Derecho internacional y los convenios internacionales.

La colocación de los niños no acompañados en centros de acogida y/o hogares de guarda no garantiza la protección efectiva de los MENAS. Las medidas de protección deberán ir orientadas a mantener al menor en un entorno familiar, siempre que sea posible. En este contexto, las administraciones responsables de protección de los MENAS tienen varias opciones, si bien, la institución de la Kafala como medida protectora al menor es la medida más efectiva en caso de los menores refugiados sirios que se encuentran actualmente en Europa.

Pese a los esfuerzos realizados y el avance conseguido en la materia de la protección de los menores no acompañados (MENAS), las resoluciones establecidas a nivel de la Unión Europea no contienen garantías suficientes para la salvaguarda de los derechos de los menores no acompañados, tampoco las resoluciones tienen fuerza vinculante para los

102 FERNÁNDEZ ROZAS, J.C., Derecho Internacional Privado, 10ª ed., Cizur Menor (Civitas-Thomson Reuters), 2018, p. 409.

RJUAM, n. ${ }^{\circ}$ 39, 2019-I, pp. 9-43

ISSN: 1575-720-X 
Estados miembros. Es necesario, por tanto, desde la visión de este análisis, decretar nuevas resoluciones de carácter vinculante para los Estados miembros, de modo que aseguren un ejercicio eficaz de los derechos de los menores no acompañados que se encuentran en la Unión Europea, atendiendo a la normativa internacional, en especial, a la fuerza vinculante del Convenio de los Derechos del niño de la ONU. Esta necesidad de encontrar soluciones prácticas para la ejecución de los convenios internacionales sobre la protección de los menores requiere un alto esfuerzo y cooperación entre las diferentes instituciones internacionales y los Estados Partes, de modo que reduzca las contradicciones existentes entre las normativas en los convenios internacionales y se establezcan las medidas oportunas en interés superior del menor, especialmente de aquellos que buscan una nueva vida huyendo de la guerra.

\section{BIBLIOGRAFÍA}

ALWAN, ABDELALLAH., La solidaridad social en el Islam, Cairo (Dar Al-Asslam), 2007.

ALLUEVA AZNAR, L., "Situaciones de riesgo y desamparo en la protección de menores», Revista para el Análisis del Derecho Indret, 4/2011.

AMAIA BRAVO, Mª SANTOS-GONZÁLES, I., «Menores extranjeros no acompañados en España: necesidades y modelos de intervención», Psychosocial Intervention, vol. 26, 2017.

AMADOR, MARTA, «La respuesta europea a la crisis migratoria siria, Refugiados y desplazados en el mundo», Plan de acogida al Refugiado de UCM d + I; UNICEF ACNUR: España, 2015: El año de la crisis de refugiados en Europa. Disponible en <https://www.ucm.es/data/cont/media/www/pag-91729/1-17\%20Respuestaeuropea-crisis-migratoria_MartaAmador.pdf $>$. [Consultado el 28/08/2019].

ARCE FERNÁNDEZ, I., Cuaderno Recopilatorio de Legislación Relativa a Menores de Edad, Oviedo (Consejería de Servicios y Derechos Sociales del Principado de Asturias), 2017.

BÉNÉDICTE MASSON., “"Mineurs isolés étrangers”: le sens d'une appellation», Migrations Société, 2010/3-4, (N 129-130), pp. 115-128. Disponible en: <https:/www.cairn.info/revue-migrations-societe-2010-3-page-115.htm\#>. [Consultado el 18/03/2019].

BORRÁS A.; MERNISSI S. (ed.)., El Islam jurídico y Europa, Icaria Editorial, Barcelona, 1998.

BRAVO RODRÍGUEZ, Mª ., «La situación de menores no acompañados en España», Conferencia regional sobre «las Migraciones de los menores no acompañados; 
actuar de acuerdo con el interés superior del menor», Consejo de Europa, MálagaEspaña, 2005.

CALVO CARAVACA, A. Y CARRASCOSA GONZÁLEZ, J., Derecho Internacional Privado, vol. II, ed.18 ${ }^{\circ}$, Granada, (Comares) 2018.

CALVO CARAVACA, A.; CARRASCOSA GONZÁLEZ, J.; CASTELLANOS RUIZ, E., Derecho de familia internacional, ed.4. ${ }^{\circ}$, Colex, Madrid, 2008.

DÍEZ MORRÁS. J., «Indefinición del interés superior del menor extranjero no acompañado en perjuicio de su protección», Protección Jurídica, responsabilidad penal y mediación en justicia de menores, REDUR, Universidad de Rioja, Logroño, 2012, pp. 95-104. Disponible en: <https://www.unirioja.es/dptos/dd/ redur/numero10/diez.pdf $>$.

ETIEMBLE, A., Les mineurs isolés étrangers en France, Evaluation quantitative de la population accueillie á lAide Sociale á lEnfance - Les termes de l'accueil et la prise en charge, Rennes (Quest'us), 2002.

FERNÁNDEZ ROZAS, J.C., Derecho Internacional Privado, $10^{\mathrm{a}}$ ed., Cizur Menor (Civitas-Thomson Reuters), 2018.

FERNÁNDEZ PÉREZ, A., «Funciones de las cláusulas de excepción en el proceso de localización de la norma de conflicto», Revista española de Derecho Internacional, vol. 67, n. ${ }^{\circ} 2,2015$.

HERRANZ BALLESTEROS, M., et al, Derecho Internacional Privado, Madrid (UNED), $2^{\mathrm{a}}$ ed., 2016.

JIMÉNEZ SEDANO, L.; IZQUIERDO COLLADO, J.D., «Lo que se oculta detrás de la categoría "menores marroquíes no acompañados": miedos cruzados, contradicciones europeas y consecuencias para el Trabajo Social», Cuadernos de Trabajo Social, 2013.

LAGARDE P., «Conferencia de La Haya de Derecho Internacional Privado, Informe explicativo, texto adoptado por la XVIII sesión», $H C C H, \mathrm{n}^{\circ} 44$, La Haya, Países Bajos, 2017.

LAKE, A., «Informe sobre la crisis en Siria desde el 2011 hasta 2016: No es lugar para niños», UNICEF Siria, A displaced boy in East Ghouta Rural Damscus, Siria, 2016.

Manual práctico sobre el funcionamiento del Convenio de La Haya de 1996 sobre Protección de Niños, HCCH, Hague conference on prívate international Law, Capitulo 9, La Haya, Países Bajos, 2014. 
ORTEGA GIMÉNEZ, A., «La Kafala de Derecho Islámico: Concepto, Naturaleza Jurídica, Caracteres y Efectos Jurídicos en España», Actualidad Jurídica Iberoamericana, . $^{\circ} 3,2015$, pp. 819-826.

QUIROGA, V., ALFONSO, A. Y SORIA, M., «Menores migrantes no acompañados en España, Sueños del Bolsillo», en Informe elaborado por la Grupo de Investigación IFAM, Madrid, 2010.

REQUEJO ISIDRO, M., «La protección del menor no acompañados solicitante de Asilo: Entre Estado competente y Estado responsable», Cuadernos de Derecho Transnacional, vol. 9, n. ${ }^{\circ}$ 2, 2007.

RODRÍGUEZ PINEAU, E., «La protección en España de menores cuya ley nacional prohíbe la adopción tras la reforma de la Ley 54/2007 de Adopción Internacional», Derecho Privado y Constitución, no 31, 2017.

RAMÍREZ FERNÁNDEZ, A; JIMÉNEZ ÁLVAREZ. M., (coords.), Las otras migraciones: La emigración de menores marroquies no acompañados, Madrid (Universidad Internacional de Andalucía, Akal), 2005.

SÁNCHEZ CANO, M‥J., «Adopción en España de menores en situación de Kafala y Ley nacional del adoptando», Cuadernos de Derecho Transnacional, vol. 10, n. ${ }^{\circ}$ 2, 2018.

SENOVILLA HERNÁNDEZ, D., «Situación y tratamiento de los menores extranjeros no acompañados en Europa, Un Estudio comparado de 6 países: Alemania, Bélgica, España, Francia, Italia, y Reino Unido», Observatorio internacional de Justicia Juvenil, Bélgica, 2007.

TRINIDAD NUÑEZ, P., «Los acuerdos celebrados por España en materia de menores extranjeros no acompañados en el contexto del marco jurídico de protección de los Menores extranjeros separados o no acompañados», en FRANCISCO ALDECOA, L.; JOAQUIM-J. FORNER D., (dirs.), La protección de los niños en el Derecho internacional y en las relaciones internacionales. Jornadas en conmemoración del 50 aniversario de la Declaración Universal de los Derechos del Niño y del 20 aniversario del Convenio de Nueva York sobre los Derechos del niño, Madrid (Marcial Pons), 2010, pp.267-271.

\section{Convenios y Resoluciones}

Convenio de La Haya sobre Protección del niño de 1996 relativo a la Competencia, la Ley aplicable y Medidas de Protección de los Niños, BOE núm. 291, de 2 diciembre de 2010. Disponible en: <https://www.boe.es/boe/dias/2010/12/02/pdfs/ BOE-A-2010-18510.pdf>. 
Convención de Nueva York de 1989 sobre los derechos del Niño. Disponible en: $<$ https://www.unicef.es/causas/derechos-ninos/convencion-derechos-ninos $>$.

Directiva del Parlamento Europeo y del Consejo de 13 de diciembre de 2011 (2011/95/ UE). Disponible en: <https://web.icam.es/bucket/DIRECTIVA\%2095\%20 2011\%20CALIFICACION\%20L00009-00026.pdf $>$.

Resolución del Consejo de 26 de junio de 1997 relativa a los menores no acompañados nacionales de países terceros (97/C 221/03). Disponible en: <https://eur-lex. europa.eu/legal-content/ES/ALL/?uri=CELEX:31997Y0719(02)>.

\section{Material consultado por Internet}

Alto Comisionado de las Naciones Unidas para los Refugiados (ACNUR), «Guía y Procesos en la atención a niños sin acompañantes solicitantes del asilo», 1997.

Comunicación de la Comisión al Parlamento Europeo y al Consejo, Protección de los menores migrantes, Bruselas, 2017.

«En Alemania hay más de 11.000 personas desaparecidas, incluidos unos 3.500 menores refugiados», artículo publicado en Europapress. Disponible en: <https:// www.europapress.es/internacional/noticia-alemania-hay-mas-11000-personasdesaparecidas-incluidos-3500-menores-refugiados-20181224111441.html>.

2018 cierra con al menos 12.500 menores extranjeros solos, mientras el Gobierno negocia con Marruecos su retorno. Disponible en: <https://www. lavanguardia.com/vida/20190101/453871183154/2018-cierra-con-al-menos12500-menores-extranjeros-solos-mientras-el-gobierno-negocia-con-marruecossu-retorno.html>.

HELENA MERRIMAN., «¿Por qué hay más de 10.000 niños desaparecidos en Europa?» artículo publicado en el BBC. Disponible en: <https://www.bbc.com/ mundo/noticias-internacional-37649395>.

KEMAL KIRISCI., «Turquía alberga a 3.6 millones de refugiados de la guerra en Siria». Disponible en: <https://www.semana.com/contenidos-editoriales/turquiael-peso-de-la-historia/articulo/turquia-alberga-a-36-millones-de-refugiados-dela-guerra-en-siria/596247>.

«La atención a los menores extranjeros no acompañados en el País Vasco, modelos de intervención y luces y sombras del sistema de acogida», ponencia de la Universidad de Deusto: Institución del Ararteko en las actas del coloquio internacional: «La Migración de menores extranjeros no acompañados en Europa», Vitoria-Gasteiz, 2007. 
«Menores migrantes no acompañados en la Unión Europa», artículo publicado en la Foreign Affairs. Disponible en: <http://revistafal.com/menores-migrantes-noacompanados-en-la-union-europea/>.

«España registra 2.500 menores migrantes no acompañados en 2017». Disponible en: $<$ https://www.savethechildren.es/notasprensa/espana-registro-2500-menores-migrantes-no-acompanados-en-2017-un-604-mas-que-el-ano>.

«Al menos 10.000 niños refugiados han desparecido nada más llegar a Europa», artículo publicado en el diario El Mundo. Disponible en: $<$ http://www.elmundo. es/internacional/2016/01/31/56addb6f268e3ea1318b459e.html>.

«Desaparecidos 10.000 niños refugiados en Europa». Disponible en: <https:// es.blastingnews.com/internacionales/2016/02/desaparecidos-10-000-ninosrefugiados-en-europa-00759577.html>. [Consultado el 30/07/2018].

Save The Children: «España registra 12.500 menores migrantes no acompañados en 2017», p.21. Disponible en: <https://www.savethechildren.es/notasprensa/ espana-registro-2500-menores-migrantes-no-acompanados-en-2017-un-604-masque-el-ano $>$. [Consultado el 09/01/2019]. 